\title{
Ejaculate-mediated paternal effects: evidence, mechanisms and evolutionary implications
}

\author{
Jonathan P Evans ${ }^{1}$, Alastair J Wilson², Andrea Pilastro ${ }^{3}$ and Francisco Garcia-Gonzalez ${ }^{1,4}$ \\ ${ }^{1}$ Centre for Evolutionary Biology, School of Biological Sciences, University of Western Australia, Crawley, Western \\ Australia, Australia, ${ }^{2}$ Centre for Ecology and Evolution, University of Exeter, Cornwall Campus, Penryn, UK, \\ ${ }^{3}$ Department of Biology, University of Padova, Padua, Italy and ${ }^{4}$ Estacion Biologica de Doñana-CSIC, Sevilla, Spain
}

Correspondence should be addressed to J P Evans; Email: jonathan.evans@uwa.edu.au

\begin{abstract}
Despite serving the primary objective of ensuring that at least one sperm cell reaches and fertilises an ovum, the male ejaculate (i.e. spermatozoa and seminal fluid) is a compositionally complex 'trait' that can respond phenotypically to subtle changes in conditions. In particular, recent research has shown that environmentally and genetically induced changes to ejaculates can have implications for offspring traits that are independent of the DNA sequence encoded into the sperm's haploid genome. In this review, we compile evidence from several disciplines and numerous taxonomic systems to reveal the extent of such ejaculate-mediated paternal effects (EMPEs). We consider a number of environmental and genetic factors that have been shown to impact offspring phenotypes via ejaculates, and where possible, we highlight the putative mechanistic pathways by which ejaculates can act as conduits for paternal effects. We also highlight how females themselves can influence EMPEs, and in some cases, how maternally derived sources of variance may confound attempts to test for EMPEs. Finally, we consider a range of putative evolutionary implications of EMPEs and suggest a number of potentially useful approaches for exploring these further. Overall, our review confirms that EMPEs are both widespread and varied in their effects, although studies reporting their evolutionary effects are still in their infancy.

Reproduction (2019) 157 R109-R126
\end{abstract}

\section{Introduction}

The notion that parental experiences can have implications for offspring traits and fitness is not new. Maternal effects, arising from parental care, investment in egg quality, etc., represent the most obvious route by which parents can influence their progeny's phenotypes independently of the transmission of DNA sequences (Mousseau \& Fox 1998, Qvarnstrom \& Price 2001, Wolf \& Wade 2009). However, beyond the provision of paternal care or other behaviours that directly impact offspring, the idea that fathers can similarly influence offspring phenotypes independent of transmitted alleles was, until relatively recently, considered almost heretical (Singh 2003, Varmuza 2003). Yet, in the past few years, mounting evidence has shown that ejaculates can be conduits of paternal effects, effectively transmitting information about a father's experiences and lifestyle decisions (e.g. diet, stress, social interactions) to his progeny.

Paternal effects can be defined as the influence of fathers on features of their offspring via mechanisms above the effect of transmitted alleles (Crean \& Bonduriansky 2014). Environmental factors experienced by the father will often be the ultimate source of paternal effects, and these could involve the physical environment (e.g. $\mathrm{pH}$, temperature, aridity), social or ecological factors (e.g. interactions with conspecifics, population density, mating history), experiences or emotions (e.g. stress, anxiety), toxicants (smoking, alcohol) and so on. Consequently, ejaculate-mediated paternal effects (hereafter EMPEs) arise from any such environmental factor(s) that results in the transmission of paternal effects (as defined) via ejaculates. Note that this definition does not mean that paternal effects must be entirely nongenetic. This is because while variation in ejaculate traits influencing offspring will often stem from environmental effects, there can also be amongmale genetic variance for ejaculate traits. In this case, the 'environmental' effect of the paternal ejaculate on offspring phenotype would depend in part on the father's genotype (but not that of the offspring; see 'Evolutionary implications of EMPEs' section below). The critical element for EMPEs is that there is a causal association between changes in offspring phenotype and paternal trait(s) or paternal experience(s) that are transmitted by the ejaculate (Fig. 1 for a conceptual scheme outlining the modes of action for EMPEs). This causal association may occur independently of, or through an interaction with, maternal influences on offspring phenotype. 


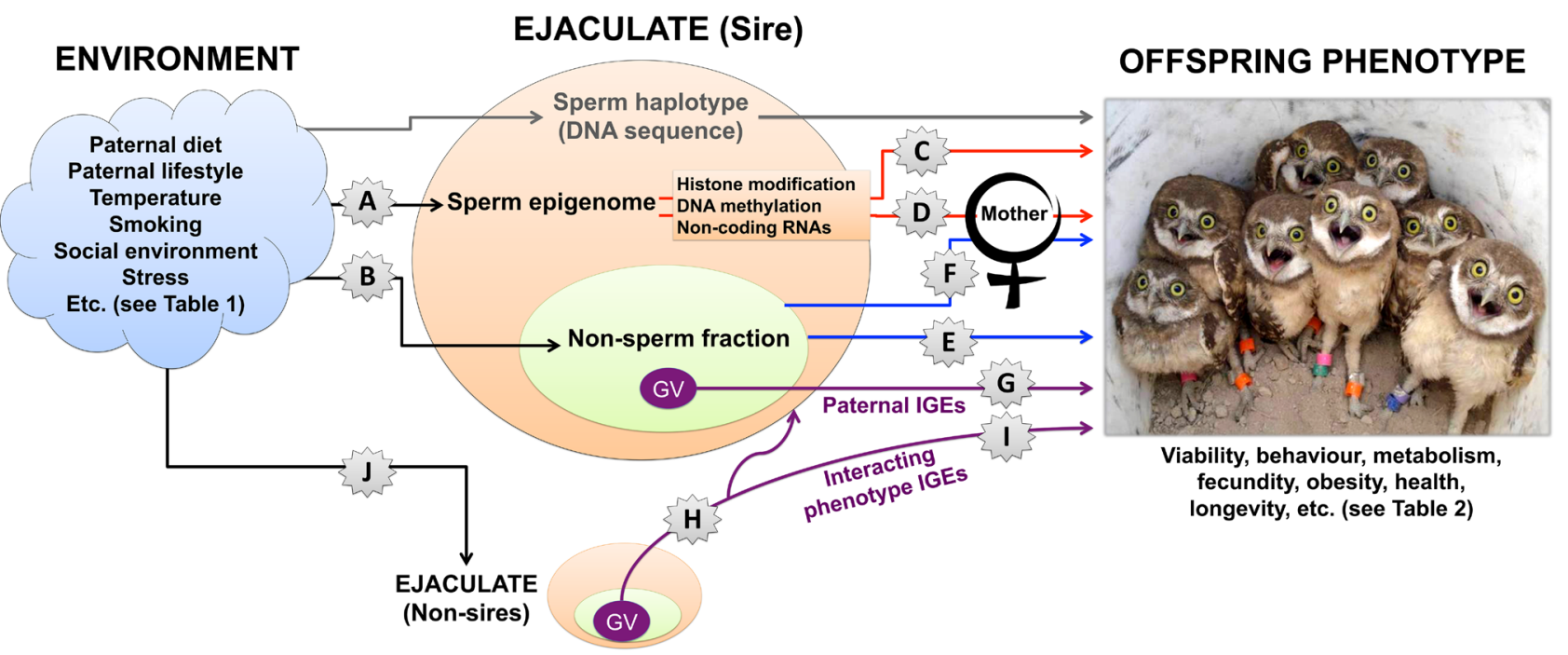

Figure 1 Modes of action for ejaculate-mediated paternal effects (EMPEs) on offspring phenotype. The modes of action for EMPEs are indicated with a grey star with a letter inside. The environment can affect the sperm epigenome (A), and the function of the non-sperm fraction of the ejaculate (B). Epigenetic mechanisms include histone modifications, DNA methylation and noncoding RNAs. The sperm epigenome can influence directly the offspring phenotype $(C)$ or may instead induce female responses (D), for example, via differential resource allocation by mothers (e.g. resource provisioning), which may ultimately affect offspring traits. The non-sperm fraction of the ejaculate not only creates an environment for the sperm, but it can also affect offspring phenotype independently of their effects on sperm, through a direct action on offspring (E) or through female-mediated effects (F). When there is additive genetic variance (GV) underlying the quantity or composition of the non-sperm fraction, and these traits shape offspring phenotype, the effects driven by the non-sperm fraction constitute a paternal indirect genetic effect (paternal IGEs) (G). Non-sires are also known to influence the phenotype of other individuals' offspring through ejaculate-mediated effects when females mate multiply $(\mathrm{H}$; see text). If there is additive genetic variance underlying these effects they will constitute interacting phenotypes indirect genetic effects (I). Non-sire experiences or environments (J) could therefore also affect other individuals' offspring through such effects. Note that the pathway denoting DNA sequence effects on offspring phenotype (top pathway in grey colour) is shown but these effects are not EMPEs. Also note that environmental factors can affect the sperm haplotype, for instance by inducing or increasing mutations in the DNA, causing DNA fragmentation or affecting DNA integrity, and this may affect offspring phenotype. However, these effects alter DNA sequence and therefore are not accommodated by our definition of EMPEs. (Picture of burrowing owls was taken by Katie McVey 'U.S. Fish and Wildlife Service' and is in the public domain 'Wikimedia Commons'.)

In this review, we compile evidence from several disciplines to reveal the scope of EMPEs across a wide range of species. For the most part, we focus on environmentally induced (in the broadest sense) changes to ejaculate phenotypes and their consequences for offspring traits and fitness, but as we note above changes in ejaculate phenotypes can have a genetic basis, which may themselves have consequences for offspring traits (Fig. 1). Where possible we also consider the mechanistic (for the most part epigenetic) pathways by which ejaculates can act as conduits for paternal effects, but also the potential role that females can play in moderating EMPEs. Finally, we consider some evolutionary implications of EMPEs and discuss promising avenues for future research. In the light of the growing number of studies providing suggestive or conclusive evidence for (i) EMPEs and their consequences for offspring phenotypes and fitness, and (ii) their mechanistic pathways, our prospective review of these topics cannot be exhaustive. Instead, we attempt to cover a representative sample of studies from both of these broad areas of research in the hope that we can work towards uniting these highly complementary fields of study and highlight where progress is needed.

\section{Environmentally induced changes in ejaculate phenotypes}

In an influential review on sperm morphological diversity, Pitnick et al. (2009) highlighted that there was a paucity of studies testing for a link between environmental heterogeneity and sperm morphological phenotype, and that these studies reveal only weak effects of the environment on sperm (but see Reinhardt et al. 2015 and Table 1). However, ejaculate traits other than sperm cells (e.g. seminal fluid proteins) can show strong environmental effects (Ramm et al. 2015, Simmons \& Lovegrove 2017). Consequently, if we consider ejaculates more broadly (i.e. the sperm cells and non-sperm components such as seminal fluid proteins and peptides, lipids, salts, etc.), the evidence linking environmental heterogeneity to variation in functionally integrated components of the ejaculate is now compelling. Together, this evidence implicates a range of environmental factors in contributing to the phenotypic diversity of ejaculate traits within individual species (for a sample of these studies see Table 1; see also the review on sperm phenotypic plasticity by Reinhardt et al. 2015). Below, we consider the emerging evidence 
Table 1 A sample of studies providing conclusive or suggestive evidence for (A) ejaculate-mediated paternal effects (EMPEs), and (B) environmental effects experienced by fathers on ejaculate traits (sperm and/or the non-sperm fraction).

\begin{tabular}{l} 
Paternal environment \\
\hline Ageing (paternal) \\
Ageing (ejaculate) \\
Alcoholism \\
Ethanol exposure \\
Exposure to (or consumption of) \\
drugs such as cocaine \\
Exposure to other toxins and \\
endocrine disruptors
\end{tabular}

Diet

Nutrition

Lifestyle (see also diet, smoking, etc.)

Reactive oxygen species (ROS)

Salinity

Smoking

Social experiences of fathers

derived from:

- Social status

- Aggressive encounters

- Stress from chronic defeat

Social experiences of fathers derived from:

- Presence of competitors or rivals

- Variation in the risk or intensity of sperm competition

- Density

- Group size

Social experiences of fathers determined by female sexual environments or female

behaviours*:

- Levels of sexual interactions

- Coexistence of ejaculates within female reproductive tract

Social experiences of fathers derived from early life traumatic stress from maternal separation

Stress

Dias and Ressier (2014), Rodgers et al. (2015)

Temperature

\section{(A) Effects on offspring phenotype through EMPEs}

Serre and Robaire (1998), García-Palomares et al. (2009a), Sharma et al. (2015), Hehar et al. (2017), Xie et al. (2018)

Tarin et al. (2000), White et al. (2008), Crean et al. (2012), Immler et al. (2014), Gasparini et al. (2017)

Bielawski et al. (2002), Abel (2004), Ouko et al. (2009), Curley et al. (2011), Braun and Champagne (2014), Soubry et al. (2014), Zuccolo et al. (2016), Wimmer et al. (2017)

Bonduriansky and Head (2007), Carone et al. (2010), Ng et al. (2010), Curley et al. (2011), Ferguson-Smith and Patti (2011), Fullston et al. (2013, 2015), Lambrot et al. (2013), Öst et al. (2014), Soubry (2015), Bonduriansky et al. (2016), Chen et al. (2016), de Castro Barbosa et al. (2016), Fontelles et al. (2016), Li et al. (2016), Schagdarsurengin and Steger (2016), Evans et al. (2017), Hehar et al. (2017), Polak et al. (2017), Donkin and Barrès (2018)

Soubry et al. (2014), Craig et al. (2017), Donkin and Barrès (2018)

Aitken (1999), Tarin et al. (2000)

Ritchie and Marshall (2013)

Pembrey et al. (2006), Linschooten et al. (2009), Beal et al. (2017)

Braun and Champagne (2014), Zajitschek et al. (2017)

Crean et al. (2013), Zajitschek et al. (2014)

Garcia-Gonzalez and Simmons (2007), Priest et al. (2008), Adler and Bonduriansky (2013), Garcia-Gonzalez and Dowling (2015)

\section{(B) Effects on ejaculate}

Oakes et al. (2003), Gasparini et al. (2010), Marshall (2015), Sharma et al. (2015), Hehar et al. (2017), Xie et al. (2018)

Tarin et al. (2000), Crean et al. (2012), Immler et al. (2014), Reinhardt et al. (2015), Gasparini et al. (2017)

Bielawski et al. (2002), He et al. (2006), Ouko et al. (2009), Sharpe (2010), Reinhardt et al. (2015), Mima et al. (2018), Rompala et al. (2018)

Eskenazi et al. (2005), Vermeulen et al. (2009), Bakos et al. (2011), Devigili et al. (2013), Fullston et al. (2013, 2015), Rahman et al. (2013, 2014), Öst et al. (2014), Chen et al. (2016), de Castro Barbosa et al. (2016), Fontelles et al. (2016), Schagdarsurengin and Steger (2016), Evans et al. (2017), Hehar et al. (2017), Immler (2018)

Sharpe (2010), Reinhardt et al. (2015), Craig et al. (2017), Ingerslev et al. (2018)

Aitken (1999), Tarin et al. (2000)

Linschooten et al. (2009), Sharpe (2010), Beal et al. (2017), Jenkins et al. (2017)

Zajitschek et al. (2017)

Wedell et al. (2002), Crean and Marshall (2008), Morrow et al. (2008), Vermeulen et al. (2009), Immler et al. (2010), Kelly and Jennions (2011), Zajitschek et al. (2014), Marshall (2015), Ramm et al. (2015), Simmons and Lovegrove (2017)

Holman (2009), den Boer et al. (2010), Simmons and Beveridge (2011), Liberti et al. (2018)
Franklin et al. (2010), Gapp et al. (2014)

Franklin et al. (2010), Gapp et al. (2014)

Franklin et al. (2010), Dias and Ressier (2014), Nargund (2015), Rodgers et al. (2015)

Blanckenhorn and Hellriegel (2002), Alavi and Cosson (2005), Adriaenssens et al. (2012), Reinhardt et al. (2015), Gasparini et al. (2018), Immler (2018)

*Includes paternal indirect genetic effects (IGEs) and interacting phenotypes (non-sire EMPEs) on offspring phenotypes. 
that these alterations in ejaculates can have remarkable implications for traits and fitness in the subsequent generation(s). First, however, we briefly consider the mechanisms by which ejaculates can act as conduits for paternal effects.

\section{Proposed mechanisms of EMPEs Epigenetic factors}

Epigenetic inheritance can be defined in a broad sense as cross-generational transmission of information that influences (offspring) phenotype but is not directly encoded in the DNA sequence. However, we share the view of others (Banta \& Richards 2018, Bonduriansky \& Day 2018) that narrower concepts of epigenetics that are focussed on specific mechanisms (notably DNA methylation, the transfer of noncoding RNAs and histone modification) are more useful.

\section{DNA methylation}

DNA methylation describes the addition of a methyl group to a nucleotide (usually cytosine), resulting in the inhibition of transcription and the modification of gene expression (and consequently offspring phenotypes) beyond that dictated by the genome's underlying DNA sequence. In mammals, this epigenetic mark is reprogrammed (following first demethylation, that is, the removal of the methyl groups, and then remethylation) twice between generations - first during gametogenesis and then during embryogenesis. Despite this extensive genome-wide reprogramming of epigenetic information during germline transmission, DNA methylation is recognised as an important mechanism of epigenetic inheritance (Wang et al. 2017, Donkin \& Barrès 2018). DNA methylation occurs regularly and naturally, but it is also susceptible to modulation by environmental cues, and evidence is accumulating that paternal experiences cause changes in DNA methylation that have consequences for offspring phenotypes (Wei et al. 2014, Donkin \& Barrès 2018, Immler 2018).

\section{Noncoding sperm RNAs}

Noncoding RNAs are functional RNA molecules that are transcribed from DNA but not translated into proteins. Numerous studies have shown that small noncoding RNAs (hereafter sncRNAs) are sensitive to various paternal environmental factors and are therefore potential sources of epigenetic inheritance (see below). Within the ejaculate, sperm cells are enriched with a diverse array of sncRNAs (Ostermeier et al. 2002), and there is evidence from humans that cell-free sncRNAs are also present within the seminal fluid (Hu et al. 2014). Direct evidence for epigenetic transmission through sperm noncoding RNAs in particular comes from a small but growing number of studies showing that paternal experiences can be transmitted to the next generation through alterations to sperm sncRNAs (see below).

The mechanisms responsible for the biogenesis of sncRNAs in sperm have been the focus of recent studies that have uncovered a potential role of the epididymis (a highly convoluted tubular structure along which maturing sperm travel from the testis to the vas deferens in birds, reptiles and mammals) in regulating the small RNA content of maturing sperm cells. For example, Sharma et al. (2016) studied the mechanism by which paternal diet affected offspring metabolism in mice, having found that protein restriction influenced small RNA levels in mature sperm. Their work showed that the levels of tRNAs were extremely low in testicular sperm, but increased in abundance as sperm matured in the epididymis, possibly due to the delivery of small RNAs from vesicles (epididymosomes) that fuse with sperm during epididymal transit (see also Rompala et al. 2018). Experimental evidence for such a mechanism comes from work showing that epididymosomes in the caput (proximal) region of the epididymis can deliver RNAs to immature sperm in vitro and that chemically tagged RNAs can be tracked in vivo from the epididymis into the maturing sperm (Sharma et al. 2018). Importantly, changes in the sperm RNA payload taking place in the epididymis have important implications for embryo fitness (Conine et al. 2018).

\section{Histone modification}

Histones, the primary protein component of chromatin that compacts DNA in eukaryotes, are susceptible to a range of modifications, and due to the role that these proteins and chromatin play in gene expression, histone modification is increasingly recognised as an important epigenetic mechanism for the transmission of paternal experiences to offspring (Donkin \& Barrès 2018, Immler 2018). Until recently, the transmission of histone-based epigenetic signatures from sperm to offspring was believed to be irrelevant in mammals, where extraordinary levels of DNA compaction in the male germ cells are achieved as a consequence of the replacement of histones by protamines (Gaucher et al. 2010). Nevertheless, many mammal species, including humans, retain a fraction (e.g., around 15\% in humans) of the haploid genome packaged within histones (i.e. in nucleosomes). Histone modification may therefore underlie the epigenetic transmission of paternal experiences to the next generations in these taxa (Miller et al. 2010). There is also emerging evidence from various animal and plant model systems that implicate histone modification in the inheritance of maternal and paternal phenotypic responses to environmental perturbations (Holeski et al. 2012, Norouzitallab et al. 2014, Schagdarsurengin \& Steger 2016). This suggests that this mechanism is involved in transgenerational inheritance mediated by the ejaculate. Indeed, Siklenka 
et al. (2015) have found in mice that the disruption of histone methylation during spermatogenesis in fathers impairs the development and survivability of their offspring, thereby demonstrating the potential of this mechanism to underlie EMPEs.

\section{Non-epigenetic mechanisms}

As we note in our introduction, our definition of EMPEs is based on the more general definition for parental effects (Wolf \& Wade 2009, Crean \& Bonduriansky 2014), which distinguish hereditary effects mediated by transmitted alleles (i.e. genetic inheritance) from nongenetic sources of variance in offspring traits and fitness. In relation to the latter, we have so far considered epigenetic factors (in the narrow sense), but as we note in the introduction, paternal effects may be transmitted through non-epigenetic mechanisms. For example, females may moderate their reproductive investment in offspring (i.e. exert differential maternal effects) according to changes in ejaculate traits (see 'Female moderation of EMPEs' section below). Furthermore, the non-sperm fraction of ejaculates contains substances (e.g. proteins, lipids) secreted by accessory glands that can ultimately influence offspring phenotypes independently of transmitted alleles (Wong et al. 2007). Indeed, in the extreme case, there is even evidence that the non-sperm fraction of ejaculates arising from males that are not the genetic father can indirectly influence offspring phenotypes (see section on 'Social experience - including non-sire EMPEs').

Although our review explicitly focuses on ejaculatemediated paternal effects, some of the evidence we present may also be attributable, at least in part, to changes in sperm DNA sequences. To take just one example, paternal ageing is associated with a range of epigenetic factors that impact offspring (Jenkins et al. 2018), but there are also well-documented effects of paternal age on the male germline that may act as contributory factors (e.g. DNA damage attributable to reaction oxygen species, mutations, DNA fragmentation, chromosomal abnormalities; Herati et al. 2017). Strictly, the direct phenotypic consequences of expressing a mutant allele inherited from the father lie outside the definition of a paternal effect. However, the extent to which environments might lead to mutational changes in sperm DNA sequence is nevertheless interesting (and likely biologically relevant) in the context of understanding how paternal experiences influence offspring traits via ejaculates.

\section{Evidence for EMPEs}

In this section, we review the emerging evidence that environmentally induced changes to sperm and ejaculate phenotypes can have implications for offspring phenotypes (see accompanying Tables 1 and 2 for summaries of these effects).

\section{Exposure to toxins and endocrine disruptors}

Paternal exposure to a range of toxins can impact traits and fitness in the next generation. For example, aflatoxins, which are poisonous by-products of the fungus Aspergillus spp., accumulate in the food chain and are known to occur at elevated rates in the semen of infertile men (Ibeh et al. 1994) where they are associated with a range of sperm abnormalities (Uriah et al. 2001). Experimental work on bulls has revealed that the exposure of ejaculates to AFB1 (the most toxic of the aflatoxins) resulted in a range of deleterious effects on sperm (e.g. reductions in sperm viability, increased DNA damage), but importantly also led to carryover effects on early embryonic stages of development (Komsky-Elbaz et al. 2018). The findings from these and other studies (e.g. see reviews by Braun \& Champagne 2014, Li et al. 2016, Fullston et al. 2017) clearly demonstrate that paternal exposure to a range of toxicants (e.g. alcohol, recreational drugs, smoking, etc.) alters offspring phenotypes (Table 1).

Studies reporting associations between paternal exposure to toxins and changes in offspring phenotypes are beginning to uncover a number of epigenetic signatures of paternal inheritance. For example, in humans, where paternal smoking is known to adversely affect offspring health (reviewed by Beal et al. 2017), recent work has revealed that paternal exposure to cigarette smoke can significantly alter genome-wide DNA methylation patterns in sperm (Jenkins et al. 2017). In mice, paternal exposure to ethanol resulted in post-transcriptional modifications to sperm sncRNAs (Rompala et al. 2018), although there is no established causal link between ethanol exposure by fathers and offspring health.

Studies have also implicated paternal chronic exposure to endocrine-disrupting chemicals to changes in sperm sncRNAs. For example, in zebrafish (Danio rerio) paternal exposure to synthetic oestrogens (17-alpha-ethinylestradiol) results in a range of disorders in offspring (e.g., skeletal and cartilage deformations, poor locomotion, etc.), mostly likely caused by an upregulation of miRNA transcripts in the testes and sperm of males exposed to these endocrine-disrupting chemicals (Valcarce et al. 2017).

\section{Ejaculate ageing}

Where males store sperm for extended periods prior to mating, pre-conception ejaculate age (as distinct from paternal age) has been implicated as a source of EMPEs. Gasparini et al. (2017) experimentally separated the effects of ejaculate age (attributable to experimental ageing of the ejaculate inside the male) from both male 
Table 2 A sample of offspring phenotypes affected or suggested to be affected by EMPEs. Review articles are also included.

\begin{tabular}{|c|c|}
\hline Offspring phenotype & References \\
\hline $\begin{array}{l}\text { Behaviour } \\
\text { Behavioural disorders, depression, } \\
\text { anxiety, etc. } \\
\text { Activity levels }\end{array}$ & $\begin{array}{l}\text { García-Palomares et al. (2009b), Curley et al. (2011), Dias and Ressier (2014), Gapp et al. (2014), } \\
\text { Zajitschek et al. (2017), Kekäläinen et al. (2018), Mashoodh et al. (2018) }\end{array}$ \\
\hline Birth defects & Lambrot et al. (2013) \\
\hline $\begin{array}{l}\text { Body size } \\
\text { Growth } \\
\text { Development }\end{array}$ & $\begin{array}{l}\text { Serre and Robaire (1998), Bielawski et al. (2002), Pembrey et al. (2006), Bonduriansky and Head } \\
\text { (2007), Ng et al. (2010), Braun and Champagne (2014), de Castro Barbosa et al. (2016), Evans et al. } \\
\text { (2017), Kekäläinen et al. (2018) }\end{array}$ \\
\hline Cancer & Aitken (1999), Xing et al. (2007), Fontelles et al. (2016), Beal et al. (2017), Braun et al. (2017) \\
\hline Condition & White et al. (2008) \\
\hline Congenital malformations & Abel (2004), Beal et al. (2017) \\
\hline Embryo & \\
\hline $\begin{array}{l}\text { Embryo viability } \\
\text { Embryo mortality } \\
\text { Embryo development } \\
\text { Hatching success }\end{array}$ & $\begin{array}{l}\text { Tarin et al. (2000), Garcia-Gonzalez and Simmons (2007), White et al. (2008), Chao et al. (2012), } \\
\text { Crean et al. (2013), Ritchie and Marshall (2013), Immler et al. (2014), Zajitschek et al. (2014), } \\
\text { Bonduriansky et al. (2016), Polak et al. (2017), Gasparini et al. (2018) }\end{array}$ \\
\hline Fecundity & Priest et al. (2008), Garcia-Gonzalez and Dowling (2015) \\
\hline $\begin{array}{l}\text { General health } \\
\text { Susceptibility to disease } \\
\text { Stress } \\
\text { Syndromes, etc. }\end{array}$ & Wei et al. (2014), Rodgers et al. (2015), Li et al. (2016), Donkin and Barrès (2018) \\
\hline $\begin{array}{l}\text { Longevity } \\
\text { Life span } \\
\text { Survival } \\
\text { Mortality } \\
\text { Ageing-associated phenotypes }\end{array}$ & $\begin{array}{l}\text { García-Palomares et al. (2009a), Crean et al. (2012), Zajitschek et al. (2014, 2018), Beal et al. (2017), } \\
\text { Gasparini et al. (2018), Xie et al. (2018) }\end{array}$ \\
\hline $\begin{array}{l}\text { Metabolism } \\
\text { Obesity }\end{array}$ & $\begin{array}{l}\text { Ng et al. (2010), Ferguson-Smith and Patti (2011), Fullston et al. (2013), Bromfield (2014), Bromfield } \\
\text { et al. (2014), Gapp et al. (2014), Öst et al. (2014), Wei et al. (2014), Chen et al. (2016), de Castro } \\
\text { Barbosa et al. (2016), Li et al. (2016), Craig et al. (2017) }\end{array}$ \\
\hline Neural phenotypes including memory & $\begin{array}{l}\text { He et al. (2006), Dias and Ressier (2014), Hehar et al. (2017), Wimmer et al. (2017), Ingerslev et al. } \\
\text { (2018), Mashoodh et al. (2018) }\end{array}$ \\
\hline Sperm quality & Gasparini et al. (2017) \\
\hline
\end{tabular}

age and potential maternal effects (e.g. that might occur during sperm storage inside the female) in the internally fertilising guppy (Poecilia reticulata) by artificially inseminating ejaculates of different ages into naïve virgin females. Offspring sired from aged sperm themselves exhibited impaired sperm quality when assayed at two time points as adults (four months and 13 months of age), suggesting a strong degree of 'permanence' in the paternal effect within first-generation males. White et al. (2008) similarly reported deleterious effects of experimentally aged ejaculates on components of offspring fitness in the kittiwake (Rissa tridactyla), although in their study, ejaculates aged within the female's reproductive tract, and so a maternal influence could not be excluded (see 'Female moderation of EMPEs' section).
There is also evidence that within-ejaculate variation in sperm age affects offspring fitness in external fertilisers. Immler et al. (2014) employed a split-clutch in vitro fertilisation design in the Atlantic salmon (Salmo salar), in which they experimentally varied the time between sperm activation and fertilisation within individual ejaculates retrieved from males. Immler et al. (2014) were therefore able to isolate the effects of ageing on ejaculates to the post-release (i.e. post-ejaculatory) environment, which enabled them to avoid potential maternal influences on offspring traits. Applying this approach to an external fertiliser enabled the authors to separate sperm 'cohorts' that differed in the time they had been active (i.e. post-activation sperm age) from individual males. This study found that offspring arising 
from fertilisations by intermediate-aged ejaculates (20s post activation) exhibited faster time to hatching than those arising from very 'young' (0s post-activation) or 'old' (40 s) ejaculate cohorts. Although the mechanisms linking ejaculate age to offspring phenotype are yet to be investigated in salmon, evidence from another externally fertilising fish, the zebrafish Danio rerio, suggests that selection on phenotypic variation among sperm within an ejaculate can favour genetically distinct (long-lived) sperm that convey fitness benefits to the next generation (Alavioon et al. 2017).

\section{Paternal age}

Paternal age has well-known effects on a range of sperm and ejaculate parameters, including sperm swimming behaviour (e.g. motility), sperm DNA integrity, telomere length, chromosomal structure and a range of epigenetic factors (reviewed by Sharma et al. 2015; see also Table 1). However, it is now apparent that these changes to ejaculates can also have consequences for offspring health and fitness parameters (Table 1). In rodents, for example, advanced paternal age is associated with a decline in the fertility of male offspring (CaballeroCampo et al. 2018).

Studies on rodent models are beginning to uncover the epigenetic mechanisms underlying these findings. Work on rats, for example, has shown that DNA methylation of promoter regions in sperm genes is conserved from fathers to sons, supporting the notion that this epigenetic change is responsible for the transmission of ageing-related pathologies to offspring (Hehar et al. 2017). Indeed, Hehar et al.'s (2017) work demonstrated the transmission of DNA methylation tags induced by different paternal experiences (including advanced age) from fathers to both the sperm and the brain tissue of their sons. Similarly, in a study measuring the life span of mice sired by old and young males, Xie et al. (2018) reported evidence for epigenetic alterations in the form of methylated promoters in the male germ line of old fathers and the sperm of their sons. These epigenetic marks were associated with exacerbated ageing and reduced longevity of offspring sired by older fathers (Xie et al. 2018). Thus, the consequences of advanced paternal age on a range of offspring traits (Table 1) may arise through a range of epigenetic factors (reviewed by Herati et al. 2017), but it is important to note that such effects may also be attributable to ageing-related DNA damage (Gunes et al. 2016, Bisht et al. 2017).

\section{Diet, nutrition and paternal obesity}

There is widespread evidence that ejaculates can vary according to paternal nutrition (Table 1) and emerging evidence that diet-induced effects on ejaculates can also impact offspring (Bonduriansky \& Head 2007, FergusonSmith \& Patti 2011, Fullston et al. 2013, Schagdarsurengin
\& Steger 2016, Evans et al. 2017, Polak et al. 2017; Table 1 for further studies). There is also suggestive evidence that such paternal dietary effects on offspring phenotypes may operate through seminal plasma as a modulating factor. For example, Bonduriansky et al. (2016) studied diet-induced parental effects in the neriid fly (Telostylinus angusticollis) and reported complex, nonlinear (and differential) patterns of diet-modulated paternal effects that varied by offspring sex and may be mediated by seminal fluid. Together these and other studies (Garcia-Gonzalez \& Simmons 2007, Crean et al. 2014) suggest that 'non-sperm' ejaculate components can act as condition-dependent signals of a male's nutritional status that are transmitted to subsequent generations, albeit via unknown mechanistic processes (Bromfield 2014, Macartney et al. 2018).

Male obesity can also be a source of EMPEs. For example, in humans and animal models there is emerging evidence that a father's high-fat diet prior to conception increases the risk of metabolic disturbances and other pathological traits in offspring (reviewed by Craig et al. 2017, Fleming et al. 2018). Remarkably, Fontelles et al. (2016) reported that in mice, dietinduced paternal obesity around the time of conception is associated with a heightened risk of breast cancer in daughters. Experimental work on rodents has explored the mechanistic basis for such effects, revealing that diet-induced paternal obesity modulates sperm miRNA content and germ cell methylation status, which in turn are linked to increased levels of obesity and insulin resistance in both male and female offspring for up to two generations (Fullston et al. 2013). Furthermore, the use of micro-injection of both testis and sperm sncRNAs of male mice fed a high-fat, high-caloric (i.e. westernstyle) diet into one-cell embryos resulted in similar pathological traits in the adult offspring that were not observed when RNAs from healthy control males were used (Grandjean et al. 2015).

\section{Thermal environment}

Within ecologically relevant boundaries, spermatozoa of some species can be remarkably tolerant to changes in temperature in terms of their absolute capacity to activate and fertilise oocytes. Nevertheless, there is evidence that changes in temperature experienced by males (or their ejaculates) prior to conception can have important implications for offspring fitness (Gasparini et al. 2018, Kekäläinen et al. 2018). Recent work suggests that epigenetic alterations to the germline may drive such effects. For example, Klosin et al. (2017) reported longlasting epigenetic 'memory' of temperature experiences in Caenorhabditis elegans, where heat stress imposed on adults resulted in altered gene expression for up to 14 generations after return to baseline temperatures an effect attributable to (epigenetic) inheritance through both sperm and oocytes. 


\section{Social experience - including non-sire EMPEs}

Social environments provided by interacting conspecifics can provide an additional source of variance in ejaculate traits that lead to paternal effects on offspring behaviour and physiology (Garcia-Gonzalez 2018). For example, recent work by Zajitschek et al. (2017) on the externally fertilising zebrafish (Danio rerio) revealed that the experimental manipulation of a male's social status influenced the velocity of his sperm and that these socially induced changes to ejaculate phenotypes impacted offspring behaviour (activity levels). The use of in vitro fertilisation to deliver ejaculates from the different treatments to externally shed eggs enabled the researchers to attribute these cross-generational effects exclusively to EMPEs.

There is also evidence from insects that offspring traits can be shaped by complex interactions between the genetic sire's ejaculate and the presence of ejaculates from rival males in the fertilisation arena. Experimental evidence for this comes from studies of the cricket Teleogryllus oceanicus, the neriid fly $T$. angusticollis and the fruit fly Drosophila melanogaster and suggests that ejaculates from non-sires also impose effects on offspring of the genetic father. In T. oceanicus, variation in embryo viability can be unambiguously attributed to variation in the sire's and non-sires' non-sperm ejaculate component (Garcia-Gonzalez \& Simmons 2005, L W Simmons \& M Lovegrove, unpublished observations). Put differently, the viability of a focal offspring is actually influenced by the phenotypes of its father's rivals. Similarly, in T. angusticollis, offspring body size is influenced by environmentally induced changes in the condition of the mother's previous mate - an effect attributed to the condition-dependent influence of male seminal fluid on developing oocytes (Crean et al. 2014). Finally, in D. melanogaster the receipt by mothers of additional seminal fluid proteins from sterile males increases the reproductive success of daughters, indicating that the seminal fluid components (in this case main-cell accessory gland proteins) from nonsire ejaculates are responsible for changes in offspring phenotype, possibly through female mediation (Priest et al. 2008).

\section{Paternal stress}

Much of the experimental evidence for environmentally induced EMPEs comes from studies of paternal stress. Although the concept of stress is arguably broad enough to encompass many of the scenarios highlighted above (e.g. thermal stress, nutritional stress), it has been invoked in particular in relation to social and psychological experiences such as maternal separation, adverse childhood experiences, chronic social instability, reductions in maternal care, chronic social defeat stress and so on (for a recent review, Wang et al. 2017).
In rodents, there is widespread evidence that the exposure of males to a variety of psychological stresses, such as social instability (Saavedra-Rodriguez \& Feig 2013), social defeat (Dietz et al. 2011), physical restraint (He et al. 2016) and early maternal separation (Franklin et al. 2010) result in behavioural changes (e.g. higher anxiety, depression-like behaviours) across generations. Evidence from humans similarly links adverse paternal experiences to psychological stress disorders in the next generation (Pang et al. 2017).

Small RNAs may play a prominent role in the epigenetic transmission of paternal stress to subsequent generations (Spadafora 2018). Remarkably, recent molecular work on humans and mice has implicated changes in the same family of sperm miRNAs in both groups. Specifically, Dickson et al. (2018) reported that multiple sperm miRNAs of the same (miR-449/34) family were suppressed in males with high adverse childhood experiences and chronic social instability scores in men and mice, respectively. Moreover, Dickson et al. (2018) found that the reductions in these sperm miRNAs in stressed male mice persisted in the sperm of male offspring, strongly suggesting that the transmission of stress-associated behaviours across generations were attributable to the epigenetic regulation of these sperm miRNAs. Furthermore, Gapp et al.'s (2014) influential study of mice revealed that chronic and unpredictable maternal separation early in life altered miRNA expression and subsequently behavioural and metabolic responses in progeny (see also Rowold et al. 2017 for a recent review on intergenerational transmission of trauma). Importantly, Gapp et al. (2014) showed that when sperm from traumatised males were injected into fertilised oocytes, the same behavioural and metabolic alterations were seen in the resulting offspring, confirming a causal link between sperm RNAs and the transmission of acquired traits to offspring.

Further detailed work on stress in rodent models has revealed a potentially complex interplay between sperm RNAs and maternal mRNA. Rodgers et al. (2013), for example, identified nine miRNAs following chronic exposure to stress in paternal mice and showed that their heightened expression was associated with a reduced hypothalamic-pituitary-adrenal (HPA) axis (stress-regulating system) response in offspring. To confirm that sperm miRNAs were the mechanism of epigenetic transmission responsible for the blunted HPA response in offspring, Rodgers et al. (2015) subsequently micro-injected the nine sperm miRNAs into singlecelled zygotes and implanted these into surrogate females. This treatment resulted in a striking congruence between offspring phenotype and the paternal stress response, confirming the role of sperm RNA as the mechanistic link between paternal experience and the altered offspring phenotypes. However, the authors also found that sperm miRNAs specifically target stores of maternal mRNA, leading to the post-transcriptional 
silencing of genes associated with the development of neurodevelopment and stress reactions in the developing embryo. This latter finding suggests that the paternal epigenome interacts with maternal genes to influence embryonic development.

\section{Female moderation of EMPEs}

The emerging evidence linking pre-conception paternal experiences to changes in offspring traits clearly implicates EMPEs in driving these effects. However, before we can draw firm conclusions in this regard, we must also consider the possible role that mothers play in moderating these paternal effects on offspring traits. In particular, as we first highlight in this section, differential patterns of maternal investment may confound associations between paternal experiences and offspring traits.

\section{Differential patterns of maternal investment}

Behavioural and evolutionary studies reveal that females plastically adjust patterns of reproductive investment in response to cues obtained from their mates. Specifically, there is support for both the differential allocation hypothesis (which posits that females should increase reproductive investment when mating with attractive males; Burley 1986, Sheldon 2000) and the contrasting reproductive compensation hypothesis (which predicts females should increase investment when paired to an unattractive male in order to offset disadvantages that offspring might inherit from fathers; Gowaty et al. 2007).

For our purposes, the occurrence of differential patterns of maternal investment raises the salient point that a female's reproductive investment in her offspring can be altered according to phenotypic characteristics of her mate. This has important implications for the design and interpretation of studies that test for EMPEs (Curley et al. 2011, Crean \& Bonduriansky 2014). The first is that females may alter investment in offspring according to changes in male ejaculate traits. Since the consequences for offspring traits and fitness would thus depend on both parents (independently of direct inheritance of genes) we refer to this scenario as a 'maternal effect modulated EMPE'. Second, and more problematically in the context of this discussion, differential maternal investment may confound tests for EMPEs if not adequately controlled in experimental designs. Imagine, for example, that experimental changes in diet quality (e.g. reduction in ingested carotenoids) causes changes in ejaculate traits but also changes in a male's attractiveness to females (e.g. reduction in plumage brightness). Clearly any change in female investment caused by the change in the male's attractiveness (independent of any effect on ejaculates) would not constitute an EMPE. Thus, maternal effect-modulated EMPEs are biologically interesting in the context of tests for EMPEs, but failure to recognise that differential maternal effects could, on occasion, confound experimental tests for EMPEs is problematic.

\section{Evidence that maternal effects can modulate EMPEs}

To test the possible influence of females in modulating EMPEs, Mashoodh et al. (2018) employed embryo transfer (effectively cross-fostering) in mice to experimentally separate EMPEs from maternally derived sources of variance in offspring fitness. They showed that nutritional restriction in fathers influenced growth rate, hypothalamic gene expression and the behaviour of female offspring. However, the authors also showed that following natural copulations, females mated to food-restricted males exhibited compensatory patterns of reproductive investment (increased pre- and postnatal care), which reversed the phenotypic outcomes generated by EMPEs. This shows that mothers can modulate the impact of paternal influences on offspring development, but also serves as a cautionary tale about the need to account for differential maternal effects when testing for EMPEs.

In internal fertilisers, the conception environment provides numerous potential opportunities for ejaculatefemale interactions that may influence offspring phenotypes. For example, in mice, the male's seminal plasma is known to influence offspring phenotype, possibly due to the role that it plays in protecting sperm from reactive oxygen species (ROS)-induced DNA fragmentation within the female's reproductive tract (Bromfield et al. 2014). Bromfield et al. (2014) used experimental approaches that were able to disentangle the individual and possible interactive effects of male and female regulatory factors and reported that the male's seminal plasma indirectly influences offspring phenotypes via female factors that regulate embryo development. This dual function of seminal plasma (sperm protection and signalling to the female reproductive tract) underscores the need to understand (and in some cases experimentally account for) maternal effects when evaluating the importance of EMPEs.

Possible female influences on the transmission of EMPEs may be mitigated under conditions that deny females behavioural control over mating. For example, a series of studies of internally (Evans et al. 2017, Gasparini et al. 2017) and externally fertilising species (Crean et al. 2013, Zajitschek et al. 2014) have employed artificial insemination and IVF, respectively, in order to experimentally preclude maternal effects when testing for EMPEs. Dietz et al. (2011) went further by employing an experimental protocol that both allowed and denied females behavioural control over mating when testing for paternal transmission of stress-induced pathologies to offspring in mice. In that study, the authors tested the effects of paternal exposure to 'chronic social defeat stress' (where males are successively subjected to novel aggressive mice) on a range of stress-induced pathologies 
in their offspring. Dietz et al. (2011) reported significant increases in depression and anxiety-like traits, as well as putative hormonal biomarkers of depression, in the offspring sired by chronically stressed fathers. By comparing the intergenerational effects of paternal stress in offspring bred from mice before and after the father experienced defeat, the authors were able to isolate the effect of social experience on offspring traits from pre-existing diathesis (i.e. heritable predisposition for defeat). However, the authors subsequently found that these effects, which were evident after natural matings, were largely absent when IVF was used, strongly arguing against epigenetic alterations in the germ cells. An alternative explanation, which was also considered by Dietz et al. (2011), is that females may have detected levels of paternal stress and altered their reproductive investment towards affected litters accordingly.

\section{Evolutionary implications of EMPEs}

Where EMPEs generate fitness variation, it is likely that they will also influence evolutionary dynamics. To date, however, there has been little explicit evaluation of this possibility for EMPEs specifically or for paternal effects more generally (but see Qvarnstrom \& Price 2001, Bonduriansky \& Day 2009, Jablonka \& Raz 2009, Danchin et al. 2011 for a discussion of these issues). Nonetheless, by drawing parallels with a large evolutionary quantitative genetic literature on maternal effects (reviewed by Hadfield 2012), we can make general predictions about the potential consequences of EMPEs for trait evolution and identify priorities for future research. We acknowledge that not all features of epigenetic mechanisms (as highlighted above) are readily accommodated by current quantitative genetic theory (Banta \& Richards 2018), but this framework is, at present, the most developed and pragmatic starting point for understanding the evolutionary consequences of EMPEs.

Before continuing, two points about quantitative genetic approaches are worth emphasising to the unfamiliar reader. First, at least in its classical form, quantitative genetics describes inheritance and trait evolution using statistical parameters. No explicit knowledge of underlying molecular mechanisms is needed and 'genes' are conceptualised as 'units of inheritance' rather than being defined on the basis of an observable DNA sequence. In this framework, a paternal (or maternal) effect on offspring phenotype remains defined as an effect over and above that of alleles inherited by the offspring, but may still be described as 'genetic' if it arises from heritable variation among fathers (or mothers) for some trait (e.g. an ejaculate trait). The key point here is that offspring phenotype is influenced not directly by expression of its own genes, but indirectly by expression of genes in the father (via some paternal ejaculate trait). Paternal effects can therefore constitute a particular form of indirect genetic effect (IGE), defined as a causal influence of the expression of genes in one individual on the phenotype of another (Wolf et al. 1998, McAdam et al. 2014). Note that IGEs are a general phenomenon and may arise from interactions among individuals with any relationship structure (or with none; Moore et al. 1997, Bijma 2014). Notably, a molecular geneticist may well describe this indirect 'genetic' phenomenon as 'epigenetic' if there is involvement of epigenetic factors in a strictly mechanistic sense (i.e., methylation, histone modification, sncRNAs). These semantic issues raise obvious potential for misunderstanding and confusion (Deans \& Maggert 2015, Banta \& Richards 2018 for a useful discussion of these issues).

Second, in the context of predicting evolutionary trait dynamics, the most important questions are not whether and how (mechanistically) paternal effects arise, but rather to what extent they contribute to genetic variation for the offspring trait in a population. This is because evolutionary change in a trait's mean is predicted (in the simplest case) as the product of selection strength and narrow-sense heritability $\left(h^{2}\right.$, the proportion of trait variance attributable to the direct (additive) effect of genes on the phenotypes of their bearers; Falconer \& Mackay 1996). However, if present, paternal genetic effects represent an additional source of genetic variation for the focal (e.g. offspring) trait that will impact any response to selection.

\section{Quantitative genetic approaches to characterising EMPEs}

Given an appropriate data structure, it should be possible to estimate the 'paternal genetic variance' in an offspring trait using extensions of standard quantitative genetic methods (e.g., linear mixed-effect models). This is the variance in the offspring trait that arises from paternal genetic effects as defined earlier. Note, however, that ANOVA on data from a standard paternal half-sib full sib breeding design would not allow this as the observed among-sire variance will fail to separate (direct) additive genetic inheritance and paternal effects (whether genetic or otherwise). Indeed, the standard approach of using among-sire variance to calculate heritability necessarily assumes an absence of paternal effects. Consequently, it will be necessary to explicitly model an effect of paternal genotype over and above the additive effect of an offspring's own genotype (e.g. using an extended 'animal model' framework; Wilson et al. 2010). Coupled with data on ejaculate traits, multivariate quantitative genetic analyses could be used to test the hypothesised drivers of this variance (e.g. using the 'hybrid' strategy suggested by McAdam et al. 2014). Existing evolutionary theory on maternal effects (Willham 1963, Kirkpatrick \& Lande 1989) could then be readily co-opted to the paternal case to predictively model the consequences of paternal genetic effects. 
To date, we are not aware of any studies that have taken the approach outlined above, and estimates of paternal genetic variance (as distinct from sire variance), whether mediated by ejaculates or not, are conspicuous by their absence. Consequently, while ejaculate traits have clearly been shaped by past selection processes (Fitzpatrick et al. 2009, Fitzpatrick \& Lupold 2014, Lupold \& Fitzpatrick 2015), whether or not EMPEs play a major role in determining contemporary selection responses is an open question. Nonetheless, several of the studies on EMPEs reviewed above have concluded that these effects on offspring arise from variation in paternal traits known to be heritable (Garcia-Gonzalez \& Simmons 2005, 2007). Logically, this implies that there is a causal relationship between paternal genotype and offspring phenotype (i.e. paternal genetic effects). An additional but as yet untested possibility is that the influence of paternal environmental effects on offspring phenotype is contingent on paternal genotype. This presence of such a paternal genotype-by-environment interaction would mean that fathers vary genetically not just in (average) ejaculate traits, but also in plasticity of those ejaculate traits. Though not immediately apparent (without recourse to algebra!) in this scenario the amount of paternal genetic variance present for an offspring trait will vary as a function of environmental conditions experienced by fathers (Roff \& Wilson 2014).

\section{Evolutionary consequences of genetically determined EMPEs}

Irrespective of whether paternal genetic variance is stable across environments, what exactly are the evolutionary consequences of its presence for offspring traits under selection? It is tempting to assume that an additional source of genetic variance will necessarily mean a faster selection response for an affected offspring trait than would be expected from the direct heritability. Though possible, this outcome is not inevitable for two reasons. The first is statistical; as we note above, common methods used to estimate $\mathrm{h}^{2}$ (e.g. ANOVA on data from paternal half-sibling mating designs) will be upwardly biased if paternal effects are present but not accounted for in the analysis (as recently demonstrated empirically; L W Simmons \& M Lovegrove, unpublished observations). In other words, we may currently be unaware of one source of genetic variance (paternal), but have an inflated view of the other (the direct additive effect; see 'Conclusions and future directions' section). The second is biological: the paternal trait that gives rise to (EM)PEs and the affected offspring trait may not be genetically independent of each other. Genetic correlations, which arise due to underlying linkage disequilibrium and/or pleiotropy, mean that evolution of the offspring trait will cause correlated evolution of the paternal trait. For instance, imagine a hypothetical situation in which a gene influencing growth rate when expressed in juveniles has pleiotropic effects on an ejaculate trait when expressed in adult males. Now suppose that this ejaculate trait is itself a source of EMPEs on offspring growth. Selecting for increased juvenile growth will now cause evolution of the ejaculate trait as well. However, will alleles with positive direct genetic effects on growth (i.e. when expressed by the juvenile) have positive or negative indirect genetic effects when expressed in a father? Either is possible and theoretical models make clear that, depending on the sign and size of correlation between direct and indirect genetic effects, coevolution of the paternal trait can either accelerate or reduce change in the offspring trait relative to naïve expectations (Bijma \& Wade 2008).

Thus, if genetic correlations occur there will be coevolution between paternal (ejaculate) and offspring traits. While this is true if only the offspring trait is under selection, additional complexity arises in the plausible scenario that the paternal trait has direct fitness consequences for the father (as opposed to indirect consequences via offspring fitness). This is clearly seen in the more widely studied context of maternal effects. Consider an offspring trait (e.g. growth) under positive selection and subject to maternal effects arising from a maternal care trait (e.g. milk quality in a mammal). Since producing better milk will increase offspring growth, and thus fitness, it may be considered an 'adaptive' maternal effect. However, care is costly to the female (in terms of future survival and/or fecundity) and so selected against through her own fitness. Such transgenerational 'parent-offspring conflict' is central to our understanding of parental care evolution (Royle 2012), and may be similarly important if there are significant metabolic costs incurred by males in establishing and maintaining the epigenetic machinery underlying EMPEs (Macartney et al. 2018).

\section{Are EMPEs adaptive or non-adaptive?}

At face value, much of the evidence presented in this review suggests that EMPEs are often harmful for offspring. For example, offspring from chronically stressed fathers typically present anxiety or depressionlike behavioural symptoms themselves, which clearly appear to be detrimental to their welfare. However, it has also been argued that the transfer of 'information' about parental conditions to offspring can prepare the next generation for those same prevailing conditions (Bonduriansky \& Day 2009 and references therein). Thus, the question becomes: would offspring suffering symptoms reminiscent of their father do better in the same (harsh) environment that brought on the stress response in their father compared to individuals that were 'ill-prepared' for such conditions? To test this idea, environmental manipulation needs to be carried out in both the paternal and offspring generation, with some 
measure of 'fitness' (e.g. survival, reproductive success) carried out in the offspring generation (Uller et al. 2013).

Suggestive evidence for such adaptive parental effects comes from a study of a broadcast spawning marine tubeworm (Hydroides diramphus), where embryos and larvae arising from males (and females) whose sperm (or eggs) were exposed to varying salinity levels exhibited enhanced survival when experiencing salinities that matched the most recent experience of their parents (Jensen et al. 2014). Similar suggestive evidence that EMPEs can adaptively prepare offspring for future environmental conditions comes from a high profile study of mice, revealing that when males from the ancestral (F0) generation were exposed to odours associated with stressful conditions prior to conception, subsequent generations (F1 and F2) exhibited appropriate stimulus-specific responses to those same odours (Dias \& Ressier 2014, but see commentary on this paper by Francis 2014). Together, these and other similar studies (Chirgwin et al. 2018) support the idea that parental effects can bridge the divide between shortterm adaptive responses (on an ecological timescale) and long-term evolutionary adaptations.

On the other hand, the transfer of paternal experiences via EMPEs may reflect non-adaptive 'noise' arising from epigenetic factors that disrupt the paternal germline. For example, it has been argued that the epigenetic transmission of disease susceptibility in mammals most likely reflects symptoms of ancestral disease states, which in no way can be considered adaptive for affected offspring (e.g. see review by Gluckman et al. 2007). EMPEs may also facilitate the spread of 'selfish genetic elements' (i.e. genetic sequences that are passed on to offspring with no contribution to the fitness of their hosts), or generate parent-offspring conflict, where nongenetically transmitted factors can have different fitness consequences for parents and their offspring (e.g. see discussions by Bonduriansky \& Day 2009, Immler 2018). Overall, it is clear that we need more empirical and theoretical work to allow us to draw broad conclusions about the likely fitness consequences of EMPEs.

\section{EMPEs and sexual conflict}

Sexual conflict, where males and females have divergent evolutionary interests over reproduction (Parker 1979), is recognised as a potent evolutionary force (Arnqvist \& Rowe 2005). A question of particular relevance to this review is whether EMPEs play a role in sexual conflict, especially in the light of two decades of research showing that in some species males harm females through the action of seminal fluid products (Chapman et al. 1995, Arnqvist \& Rowe 2005, Shi \& Murphy 2014). In Drosophila melanogaster, for example, seminal fluids transferred by the male during copulation induce a series of physiological changes in females, including a reduction in receptivity and an increase in oviposition rates, both of which ultimately reduce female longevity (Chapman et al. 1995, Wolfner 2002, 2009, Kubli 2003). In the context of EMPEs, the receipt of accessory gland products by females is also associated with phenotypic changes in their offspring, such as the enhanced fecundity of daughters from mothers that are exposed to seminal fluid (Priest et al. 2008). Using gene-knockdown techniques, Wigby and Chapman (2005) generated D. melanogaster males that were deficient in the production of the sex peptide, a seminal protein responsible for many of the physiological, behavioural and fitness alterations in females discussed earlier. Wigby and Chapman (2005) found that females continuously exposed to these males produced offspring with higher egg-to-adult viability than control females. These findings suggest that sexual conflict and EMPEs (with or without female modulation) are likely to be related phenomena, but the evidence is scant and it is mostly restricted to D. melanogaster.

Further suggestive evidence for a role of EMPEs in sexual conflict in a different system comes from Simmons and Garcia-Gonzalez's (2007) quantitative genetic analysis of paternal effects in Australian field crickets (Teleogryllus oceanicus). Here, the authors suggested that paternal effects might shift females from their naturally selected optima in regards to their fecundity and the viability of their offspring. Specifically, Simmons and Garcia-Gonzalez (2007) reported a negative genetic correlation between a female's ovary weight, which determines her fecundity, and her sons' investment into the accessory gland, which determines paternal effects on embryo viability (Garcia-Gonzalez \& Simmons 2007). This genetic trade-off hints at the existence of EMPEs-mediated sexual conflict over a female's optimal fecundity and embryo viability.

Despite these tantalising insights, there is a clear need for greater empirical progress (e.g., experimentally manipulating the composition of seminal fluid and testing concomitant effects on both female and offspring fitness) and theoretical work to more fully evaluate the role that EMPEs play in sexual conflict, ideally focusing on a greater range of study systems (including vertebrate models). An improved understanding of the extent, mechanisms and cross-generational consequences of gender-specific transgenerational effects on the progeny (Wang et al. 2017), and of genomic imprinting, where alleles are expressed in a parent-of-origin-specific manner (Immler 2018), will undoubtedly help to unravel the importance of EMPEs in the evolution of sexual conflict.

\section{Conclusions and future directions}

Our review highlights the considerable progress made by studies that go beyond simply documenting the direct fitness implications of environmental perturbations to ejaculate traits (e.g. loss of fertility to adult males) 
and considering the longer-term among-generational fitness consequence of these effects. Our compilation of evidence from distinct fields of study (clinical, ecological, behavioural and evolutionary) and a broad swathe of study organisms highlight a burgeoning body of evidence for EMPEs and the mechanistic (e.g. epigenetic) pathways by which ejaculates can transmit paternal effects to the next generation(s).

Our review also emphasises how EMPEs are likely to have important implications for evolutionary processes, but our ability to model these statistically using 'traditional' quantitative genetic approaches is currently limited. As we highlight above, from a statistical perspective, the presence of EMPEs may confound estimates of 'genetic' (co)variation underlying fitness traits if not modelled appropriately. We therefore require the development and implementation of statistical procedures to handle these complexities. More significantly, our review highlights how EMPEs themselves may exert important evolutionary effects by altering patterns of genetic variation (e.g. genotypeby-paternal environment interaction). Consequently, on both fronts (statistical and from an evolutionary perspective), we require experimental approaches that both test for and characterise paternal effects, evaluating their potential to bias estimates of additive genetic (co)variance, but also their possible importance for understanding a population's evolutionary potential.

Finally, it is clear from this review that there are, broadly speaking, two distinct 'camps' in which research into EMPEs is being carried out. On the one hand, evolutionary biologists have generated tantalising insights into the scope of EMPEs and understanding their implications for fitness. We envisage considerable progress in the development of quantitative approaches to further explore these topics, particularly in the field of evolutionary quantitative genetics. However, with few exceptions, the evolutionary biology camp lacks a clear grasp of the proximate mechanisms underlying the emerging evidence for EMPEs (Immler 2018). On the other hand, researchers broadly interested in clinical outcomes have amassed a vast and impressive array of studies unlocking the mechanistic pathways by which (often) deleterious paternal experiences and conditions (e.g. stress, drugs and toxins, ageing, obesity, etc.) are passed on to offspring, usually with little regard for the evolutionary origins or implications of these effects. We see enormous scope for better integration between these complementary lines of enquiry, in much the same way as the fields of medicine and public health have benefited from evolutionary insights, and vice versa (Nesse \& Stearns 2008, Losos et al. 2013).

\section{Declaration of interest}

The authors declare that there is no conflict of interest that could be perceived as prejudicing the impartiality of this review.

\section{Funding}

F G G was supported by a grant from the Spanish Ministry of Economy (CGL2016-76173-P) co-funded by the European Regional Development Fund. J P E gratefully acknowledges financial support from the University of Western Australia for sabbatical leave, during which this article was drafted.

\section{References}

Abel E 2004 Paternal contribution to fetal alcohol syndrome. Addiction Biology 9 127-133; discussion 135. (https://doi.org/10.1080/13556210 410001716980)

Adler MI \& Bonduriansky R 2013 Paternal effects on offspring fitness reflect father's social environment. Evolutionary Biology 40 288-292. (https:// doi.org/10.1007/s11692-012-9211-6)

Adriaenssens B, van Damme R, Seebacher F \& Wilson RS 2012 Sex cells in changing environments: can organisms adjust the physiological function of gametes to different temperatures? Global Change Biology 18 1797-1803. (https://doi.org/10.1111/j.1365-2486.2012.02672.x)

Aitken RJ 1999 The Amoroso Lecture: the human spermatozoon - a cell in crisis? Journal of Reproduction and Fertility 115 1-7. (https://doi. org/10.1530/jrf.0.1150001)

Alavi SMH \& Cosson J 2005 Sperm motility in fishes. I. Effects of temperature and $\mathrm{pH}$ : a review. Cell Biology International 29 101-110. (https://doi.org/10.1016/j.cellbi.2004.11.021)

Alavioon G, Hotzy C, Nakhro K, Rudolf S, Scofield DG, Zajitschek S, Maklakov AA \& Immler S 2017 Haploid selection within a single ejaculate increases offspring fitness. PNAS 114 8053-8058. (https://doi. org/10.1073/pnas.1705601114)

Arnquist G \& Rowe L 2005 Sexual Conflict. New Jersey: Princeton University Press.

Bakos HW, Mitchell M, Setchell BP \& Lane M 2011 The effect of paternal diet-induced obesity on sperm function and fertilization in a mouse model. International Journal of Andrology 34 402-410. (https://doi. org/10.1111/j.1365-2605.2010.01092.x)

Banta JA \& Richards CL 2018 Quantitative epigenetics and evolution. Heredity 121 210-224. (https://doi.org/10.1038/s41437-018-0114-x)

Beal MA, Yauk CL \& Marchetti F 2017 From sperm to offspring: assessing the heritable genetic consequences of paternal smoking and potential public health impacts. Mutation Research 773 26-50. (https://doi. org/10.1016/j.mrrev.2017.04.001)

Bielawski DM, Zaher FM, Svinarich DM \& Abel EL 2002 Paternal alcohol exposure affects sperm cytosine methyltransferase messenger RNA levels. Alcoholism: Clinical and Experimental Research 26 347-351. (https://doi.org/10.1111/j.1530-0277.2002.tb02544.x)

Bijma P 2014 The quantitative genetics of indirect genetic effects: a selective review of modelling issues. Heredity 112 61-69. (https://doi. org/10.1038/hdy.2013.15)

Bijma P \& Wade MJ 2008 The joint effects of kin, multilevel selection and indirect genetic effects on response to genetic selection. Journal of Evolutionary Biology 21 1175-1188. (https://doi.org/10.1111/j.14209101.2008.01550.x)

Bisht S, Faiq M, Tolahunase M \& Dada R 2017 Oxidative stress and male infertility. Nature Reviews Urology 14 470-485. (https://doi.org/10.1038/ nrurol.2017.69)

Blanckenhorn WU \& Hellriegel B 2002 Against Bergmann's rule: fly sperm size increases with temperature. Ecology Letters 5 7-10. (https://doi. org/10.1046/j.1461-0248.2002.00298.x)

Bonduriansky R \& Day T 2009 Nongenetic inheritance and its evolutionary implications. Annual Review of Ecology, Evolution, and Systematics $\mathbf{4 0}$ 103-125. (https://doi.org/10.1146/annurev.ecolsys.39.110707.173441)

Bonduriansky R \& Day T 2018 Extended Heredity: A New Understanding of Inheritance and Evolution. Princeton, NJ: Princeton University Press.

Bonduriansky R \& Head M 2007 Maternal and paternal condition effects on offspring phenotype in Telostylinus angusticollis (Diptera: Neriidae). Journal of Evolutionary Biology 20 2379-2388. (https://doi.org/10.1111/ j.1420-9101.2007.01419.x)

Bonduriansky R, Runagall-McNaull A \& Crean AJ 2016 The nutritional geometry of parental effects: maternal and paternal macronutrient 
consumption and offspring phenotype in a neriid fly. Functional Ecology 30 1675-1686. (https://doi.org/10.1111/1365-2435.12643)

Braun K \& Champagne FA 2014 Paternal influences on offspring development: behavioural and epigenetic pathways. Journal of Neuroendocrinology 26 697-706. (https://doi.org/10.1111/jne.12174)

Braun JM, Messerlian C \& Hauser R 2017 Fathers matter: why it's time to consider the impact of paternal environmental exposures on children's health. Current Epidemiology Reports 4 46-55. (https://doi.org/10.1007/ s40471-017-0098-8)

Bromfield JJ 2014 Seminal fluid and reproduction: much more than previously thought. Journal of Assisted Reproduction and Genetics 31 627-636. (https://doi.org/10.1007/s10815-014-0243-y)

Bromfield JJ, Schjenken JE, Chin PY, Care AS, Jasper MJ \& Robertson SA 2014 Maternal tract factors contribute to paternal seminal fluid impact on metabolic phenotype in offspring. PNAS 111 2200-2205. (https://doi. org/10.1073/pnas.1305609111)

Burley N 1986 Sexual selection for aesthetic traits in species with biparental care. American Naturalist 127 415-445. (https://doi. org/10.1086/284493)

Caballero-Campo P, Lin W, Simbulan R, Liu XW, Feuer S, Donjacour A \& Rinaudo PF 2018 Advanced paternal age affects sperm count and anogenital distance in mouse offspring. Reproductive Sciences 25 515-522. (https://doi.org/10.1177/1933719118759441)

Carone BR, Fauquier L, Habib N, Shea JM, Hart CE, Li R, Bock C, Li C, Gu H, Zamore PD et al. 2010 Paternally induced transgenerational environmental reprogramming of metabolic gene expression in mammals. Cell 143 1084-1096. (https://doi.org/10.1016/j.cell.2010.12.008)

Chao SB, Guo L, Ou XH, Luo SM, Wang ZB, Schatten H, Gao GL \& Sun QY 2012 Heated spermatozoa: effects on embryonic development and epigenetics. Human Reproduction 27 1016-1024. (https://doi. org/10.1093/humrep/des005)

Chapman T, Liddle LF, Kalb JM, Wolfner MF \& Partridge L 1995 Cost of mating in Drosophila melanogaster females is mediated by male accessory gland products. Nature 373 241-244. (https://doi. org/10.1038/373241a0)

Chen Q, Yan M, Cao Z, Li X, Zhang Y, Shi J, Feng GH, Peng H, Zhang X, Zhang $\mathrm{Y}$ et al. 2016 Sperm tsRNAs contribute to intergenerational inheritance of an acquired metabolic disorder. Science 351 397-400. (https://doi.org/10.1126/science.aad7977)

Chirgwin E, Marshall DJ, Sgro CM \& Monro K 2018 How does parental environment influence the potential for adaptation to global change? Proceedings Biological Sciences 285 20181374. (https://doi.org/10.1098/ rspb.2018.1374)

Conine CC, Sun F, Song L, Rivera-Perez JA \& Rando OJ 2018 Small RNAs gained during epididymal transit of sperm are essential for embryonic development in mice. Developmental Cell 46 470-480.e3. (https://doi. org/10.1016/j.devcel.2018.06.024)

Craig JR, Jenkins TG, Carrell DT \& Hotaling JM 2017 Obesity, male infertility, and the sperm epigenome. Fertility and Sterility 107 848-859. (https://doi.org/10.1016/j.fertnstert.2017.02.115)

Crean AJ \& Bonduriansky R 2014 What is a paternal effect? Trends in Ecology and Evolution 29 554-559. (https://doi.org/10.1016/j. tree.2014.07.009)

Crean AJ \& Marshall DJ 2008 Gamete plasticity in a broadcast spawning marine invertebrate. PNAS 105 13508-13513. (https://doi.org/10.1073/ pnas.0806590105)

Crean AJ, Dwyer JM \& Marshall DJ 2012 Fertilization is not a new beginning: the relationship between sperm longevity and offspring performance. PLOS ONE 7 e49167. (https://doi.org/10.1371/journal. pone.0049167)

Crean AJ, Dwyer JM \& Marshall DJ 2013 Adaptive paternal effects? Experimental evidence that the paternal environment affects offspring performance. Ecology 94 2575-2582. (https://doi.org/10.1890/130184.1)

Crean AJ, Kopps AM \& Bonduriansky R 2014 Revisiting telegony: offspring inherit an acquired characteristic of their mother's previous mate. Ecology Letters 17 1545-1552. (https://doi.org/10.1111/ele.12373)

Curley JP, Mashoodh R \& Champagne FA 2011 Epigenetics and the origins of paternal effects. Hormones and Behavior 59 306-314. (https://doi. org/10.1016/j.yhbeh.2010.06.018)

Danchin É, Charmantier A, Champagne FA, Mesoudi A, Pujol B \& Blanchet S 2011 Beyond DNA: integrating inclusive inheritance into an extended theory of evolution. Nature Reviews Genetics 12 475-486. (https://doi.org/10.1038/nrg3028)

de Castro Barbosa T, Ingerslev LR, Alm PS, Versteyhe S, Massart J, Rasmussen M, Donkin I, Sjögren R, Mudry JM, Vetterli L et al. 2016 High-fat diet reprograms the epigenome of rat spermatozoa and transgenerationally affects metabolism of the offspring. Molecular Metabolism 5 184-197. (https://doi.org/10.1016/j.molmet.2015.12.002)

Deans C \& Maggert KA 2015 What do you mean, 'epigenetic'? Genetics 199 887-896. (https://doi.org/10.1534/genetics.114.173492)

den Boer SPA, Baer B \& Boomsma JJ 2010 Seminal fluid mediates ejaculate competition in social insects. Science 327 1506-1509. (https://doi. org/10.1126/science.1184709)

Devigili A, Kelley JL, Pilastro A \& Evans JP 2013 Expression of pre- and postcopulatory traits under differential dietary conditions in guppies. Behavioral Ecology 24 740-749. (https://doi.org/10.1093/beheco/ars204)

Dias BG \& Ressier KJ 2014 Parental olfactory experience influences behavior and neural structure in subsequent generations. Nature Neuroscience 17 89-96. (https://doi.org/10.1038/nn.3594)

Dickson DA, Paulus JK, Mensah V, Lem J, Saavedra-Rodriguez L, Gentry A, Pagidas K \& Feig LA 2018 Reduced levels of miRNAs 449 and 34 in sperm of mice and men exposed to early life stress. Translational Psychiatry 8 101. (https://doi.org/10.1038/s41398-018-0146-2)

Dietz DM, LaPlant Q, Watts EL, Hodes GE, Russo SJ, Feng J, Oosting RS, Vialou V \& Nestler EJ 2011 Paternal transmission of stress-induced pathologies. Biological Psychiatry 70 408-414. (https://doi.org/10.1016/j. biopsych.2011.05.005)

Donkin I \& Barrès R 2018 Sperm epigenetics and influence of environmental factors. Molecular Metabolism 14 1-11. (https://doi. org/10.1016/j.molmet.2018.02.006)

Eskenazi B, Kidd SA, Marks AR, Sloter E, Block G \& Wyrobek AJ 2005 Antioxidant intake is associated with semen quality in healthy men. Human Reproduction 20 1006-1012. (https://doi.org/10.1093/humrep/ deh725)

Evans JP, Lymbery RA, Wiid KS, Rahman MM \& Gasparini C 2017 Sperm as moderators of environmentally induced paternal effects in a livebearing fish. Biology Letters 13 20170087. (https://doi.org/10.1098/ rsbl.2017.0087)

Falconer DS \& Mackay TFC 1996 Introduction to Quantitative Genetics. London: Longman Group Ltd.

Ferguson-Smith AC \& Patti ME 2011 You are what your dad ate. Cell Metabolism 13 115-117. (https://doi.org/10.1016/j.cmet.2011.01.011)

Fitzpatrick JL \& Lupold S 2014 Sexual selection and the evolution of sperm quality. Molecular Human Reproduction 20 1180-1189. (https://doi. org/10.1093/molehr/gau067)

Fitzpatrick JL, Montgomerie R, Desjardins JK, Stiver KA, Kolm N \& Balshine S 2009 Female promiscuity promotes the evolution of faster sperm in cichlid fishes. PNAS 106 1128-1132. (https://doi.org/10.1073/ pnas.0809990106)

Fleming TP, Watkins AJ, Velazquez MA, Mathers JC, Prentice AM, Stephenson J, Barker M, Saffery R, Yajnik CS, Eckert JJ et al. 2018 Origins of lifetime health around the time of conception: causes and consequences. Lancet 391 1842-1852. (https://doi.org/10.1016/S01406736(18)30312-X)

Fontelles CC, Carney E, Clarke J, Nguyen NM, Yin C, Jin L, Cruz MI, Ong TP, Hilakivi-Clarke L \& de Assis S 2016 Paternal overweight is associated with increased breast cancer risk in daughters in a mouse model. Scientific Reports 6 11. (https://doi.org/10.1038/srep28602)

Francis G 2014 Too much success for recent groundbreaking epigenetic experiments. Genetics 198 449-451. (https://doi.org/10.1534/ genetics.114.163998)

Franklin TB, Russig H, Weiss IC, Graff J, Linder N, Michalon A, Vizi S \& Mansuy IM 2010 Epigenetic transmission of the impact of early stress across generations. Biological Psychiatry 68 408-415. (https://doi. org/10.1016/j.biopsych.2010.05.036)

Fullston T, Teague E, Palmer NO, DeBlasio MJ, Mitchell M, Corbett M, Print CG, Owens JA \& Lane M 2013 Paternal obesity initiates metabolic disturbances in two generations of mice with incomplete penetrance to the F-2 generation and alters the transcriptional profile of testis and sperm microRNA content. FASEB Journal 27 4226-4243. (https://doi. org/10.1096/fj.12-224048)

Fullston T, McPherson NO, Owens JA, Kang WX, Sandeman LY \& Lane M 2015 Paternal obesity induces metabolic and sperm disturbances in male 
offspring that are exacerbated by their exposure to an 'obesogenic' diet. Physiological Reports 3 e12336. (https://doi.org/10.14814/phy2.12336)

Fullston T, McPherson NO, Zander-Fox D \& Lane M 2017 The most common vices of men can damage fertility and the health of the next generation. Journal of Endocrinology 234 F1-F6. (https://doi. org/10.1530/JOE-16-0382)

Gapp K, Jawaid A, Sarkies P, Bohacek J, Pelczar P, Prados J, Farinelli L, Miska E \& Mansuy IM 2014 Implication of sperm RNAs in transgenerational inheritance of the effects of early trauma in mice. Nature Neuroscience 17 667-669. (https://doi.org/10.1038/nn.3695)

Garcia-Gonzalez F 2018 Indirect genetic effects-everything is special, everything is important: a comment on Bailey et al. Behavioral Ecology 29 12-18. (https://doi.org/10.1093/beheco/arx144)

Garcia-Gonzalez F \& Dowling DK 2015 Transgenerational effects of sexual interactions and sexual conflict: non-sires boost the fecundity of females in the following generation. Biology Letters 1120150067 . (https://doi. org/10.1098/rsbl.2015.0067)

Garcia-Gonzalez F \& Simmons LW 2005 The evolution of polyandry: intrinsic sire effects contribute to embryo viability. Journal of Evolutionary Biology 18 1097-1103. (https://doi.org/10.1111/j.14209101.2005.00889.x)

Garcia-Gonzalez F \& Simmons LW 2007 Paternal indirect effects on offspring viability and the benefits of polyandry. Current Biology 17 32-36. (https://doi.org/10.1016/j.cub.2006.10.054)

García-Palomares S, Navarro S, Pertusa JF, Hermenegildo C, GarcíaPérez MA, Rausell F, Cano A \& Tarín JJ 2009a Delayed fatherhood in mice decreases reproductive fitness and longevity of offspring. Biology of Reproduction 80 343-349. (https://doi.org/10.1095/ biolreprod.108.073395)

García-Palomares S, Pertusa JF, Miñarro J, García-Pérez MA, Hermenegildo C, Rausell F, Cano A \& Tarín JJ 2009b Long-term effects of delayed fatherhood in mice on postnatal development and behavioral traits of offspring. Biology of Reproduction 80 337-342. (https://doi. org/10.1095/biolreprod.108.072066)

Gasparini C, Marino IA, Boschetto C \& Pilastro A 2010 Effect of male age on sperm traits and sperm competition success in the guppy (Poecilia reticulata). Journal of Evolutionary Biology 23 124-135. (https://doi. org/10.1111/j.1420-9101.2009.01889.x)

Gasparini C, Dosselli R \& Evans JP 2017 Sperm storage by males causes changes in sperm phenotype and influences the reproductive fitness of males and their sons. Evolution Letters 1 16-25. (https://doi.org/10.1002/ evl3.2)

Gasparini C, Lu CC, Dingemanse NJ \& Tuni C 2018 Paternal-effects in a terrestrial ectotherm are temperature dependent but no evidence for adaptive effects. Functional Ecology 32 1011-1021. (https://doi. org/10.1111/1365-2435.13022)

Gaucher J, Reynoird N, Montellier E, Boussouar F, Rousseaux S \& Khochbin S 2010 From meiosis to postmeiotic events: the secrets of histone disappearance. FEBS Journal 277 599-604. (https://doi. org/10.1111/j.1742-4658.2009.07504.x)

Gluckman PD, Hanson MA \& Beedle AS 2007 Non-genomic transgenerational inheritance of disease risk. BioEssays 29 145-154. (https://doi.org/10.1002/bies.20522)

Gowaty PA, Anderson WW, Bluhm CK, Drickamer LC, Kim YK \& Moore AJ 2007 The hypothesis of reproductive compensation and its assumptions about mate preferences and offspring viability. PNAS 104 15023-15027. (https://doi.org/10.1073/pnas.0706622104)

Grandjean V, Fourre S, De Abreu DA, Derieppe MA, Remy JJ \& Rassoulzadegan M 2015 RNA-mediated paternal heredity of dietinduced obesity and metabolic disorders. Scientific Reports 518193. (https://doi.org/10.1038/srep18193)

Gunes S, Hekim GNT, Arslan MA \& Asci R 2016 Effects of aging on the male reproductive system. Journal of Assisted Reproduction and Genetics 33 441-454. (https://doi.org/10.1007/s10815-016-0663-y)

Hadfield JD 2012 The quantitative genetic theory of parental effects. In The Evolution of Parental Care. Eds NJ Royle, PT Smiseth \& M Kölliker. Oxford: Oxford University Press.

He F, Lidow IA \& Lidow MS 2006 Consequences of paternal cocaine exposure in mice. Neurotoxicology and Teratology 28 198-209. (https:// doi.org/10.1016/j.ntt.2005.12.003)

He N, Kong QQ, Wang JZ, Ning SF, Miao YL, Yuan HJ, Gong S, Cui XZ, Li CY \& Tan JH 2016 Parental life events cause behavioral difference among offspring: adult pre-gestational restraint stress reduces anxiety across generations. Scientific Reports 6 39497. (https://doi.org/10.1038/ srep39497)

Hehar H, Ma I \& Mychasiuk R 2017 Intergenerational transmission of paternal epigenetic marks: mechanisms influencing susceptibility to post-concussion symptomology in a rodent model. Scientific Reports 7 7171. (https://doi.org/10.1038/s41598-017-07784-7)

Herati AS, Zhelyazkova BH, Butler PR \& Lamb DJ 2017 Age-related alterations in the genetics and genomics of the male germ line. Fertility and Sterility 107 319-323. (https://doi.org/10.1016/j.fertnstert.2016.12.021)

Holeski LM, Jander G \& Agrawal AA 2012 Transgenerational defense induction and epigenetic inheritance in plants. Trends in Ecology and Evolution 27 618-626. (https://doi.org/10.1016/j.tree.2012.07.011)

Holman L 2009 Drosophila melanogaster seminal fluid can protect the sperm of other males. Functional Ecology 23 180-186. (https://doi. org/10.1111/j.1365-2435.2008.01509.x)

Hu L, Wu CL, Guo CC, Li HG \& Xiong CL 2014 Identification of microRNAs predominately derived from testis and epididymis in human seminal plasma. Clinical Biochemistry 47 967-972. (https://doi.org/10.1016/j. clinbiochem.2013.11.009)

Ibeh IN, Uraih N \& Ogonar JI 1994 Dietary exposure to aflatoxin in human male infertility in Benin City, Nigeria. International Journal of Fertility and Menopausal Studies 39 208-214.

Immler S 2018 The sperm factor: paternal impact beyond genes. Heredity 121 239-247. (https://doi.org/10.1038/s41437-018-0111-0)

Immler S, Pryke SR, Birkhead TR \& Griffith SC 2010 Pronounced withinindividual plasticity in sperm morphometry across social environments. Evolution; International Journal of Organic Evolution 64 1634-1643. (https://doi.org/10.1111/j.1558-5646.2009.00924.x)

Immler S, Hotzy C, Alavioon G, Petersson E \&Arnqvist G 2014 Sperm variation within a single ejaculate affects offspring development in Atlantic salmon. Biology Letters 10 20131040. (https://doi.org/10.1098/rsbl.2013.1040)

Ingerslev LR, Donkin I, Fabre O, Versteyhe S, Mechta M, Pattamaprapanont P, Mortensen B, Krarup NT \& Barrès R 2018 Endurance training remodels sperm-borne small RNA expression and methylation at neurological gene hotspots. Clinical Epigenetics 1012. (https://doi.org/10.1186/s13148-018-0446-7)

Jablonka E \& Raz G 2009 Transgenerational epigenetic inheritance: prevalence, mechanisms, and implications for the study of heredity and evolution. Quarterly Review of Biology 84 131-176. (https://doi. org/10.1086/598822)

Jenkins TG, James ER, Alonso DF, Hoidal JR, Murphy PJ, Hotaling JM, Cairns BR, Carrell DT \& Aston KI 2017 Cigarette smoking significantly alters sperm DNA methylation patterns. Andrology $\mathbf{5}$ 1089-1099. (https://doi.org/10.1111/andr.12416)

Jenkins TG, Aston KI \& Carrell DT 2018 Sperm epigenetics and aging. Translational Andrology and Urology 7 S328-S335. (https://doi. org/10.21037/tau.2018.06.10)

Jensen N, Allen RM \& Marshall DJ 2014 Adaptive maternal and paternal effects: gamete plasticity in response to parental stress. Functional Ecology 28 724-733. (https://doi.org/10.1111/1365-2435.12195)

Kekäläinen J, Oskoei P, Janhunen M, Koskinen H, Kortet R \& Huuskonen H 2018 Sperm pre-fertilization thermal environment shapes offspring phenotype and performance. Journal of Experimental Biology 221 jeb181412. (https://doi.org/10.1242/jeb.181412)

Kelly CD \& Jennions MD 2011 Sexual selection and sperm quantity: metaanalyses of strategic ejaculation. Biological Reviews of the Cambridge Philosophical Society 86 863-884. (https://doi.org/10.1111/j.1469185X.2011.00175.x)

Kirkpatrick M \& Lande R 1989 The evolution of maternal characters. Evolution; International Journal of Organic Evolution 43 485-503. (https://doi.org/10.1111/j.1558-5646.1989.tb04247.x)

Klosin A, Casas E, Hidalgo-Carcedo C, Vavouri T \& Lehner B 2017 Transgenerational transmission of environmental information in $C$. elegans. Science 356 320-323. (https://doi.org/10.1126/science. aah6412)

Komsky-Elbaz A, Saktsier M \& Roth Z 2018 Aflatoxin b1 impairs sperm quality and fertilization competence. Toxicology 393 42-50. (https://doi. org/10.1016/j.tox.2017.11.007)

Kubli E 2003 Sex-peptides: seminal peptides of the Drosophila male. Cellular and Molecular Life Sciences 60 1689-1704. (https://doi. org/10.1007/s00018-003-3052) 
Lambrot R, Xu C, Saint-Phar S, Chountalos G, Cohen T, Paquet M, Suderman M, Hallett M \& Kimmins S 2013 Low paternal dietary folate alters the mouse sperm epigenome and is associated with negative pregnancy outcomes. Nature Communications 4 2889. (https://doi. org/10.1038/ncomms3889)

Li J, Tsuprykov O, Yang XP \& Hocher B 2016 Paternal programming of offspring cardiometabolic diseases in later life. Journal of Hypertension 34 2111-2126. (https://doi.org/10.1097/HJH.0000000000001051)

Liberti J, Baer B \& Boomsma JJ 2018 Rival seminal fluid induces enhanced sperm motility in a polyandrous ant. BMC Evolutionary Biology 1828. (https://doi.org/10.1186/s12862-018-1144-y)

Linschooten JO, Van Schooten FJ, Baumgartner A, Cemeli E, van Delft J, Anderson D \& Godschalk RWL 2009 Use of spermatozoal mRNA profiles to study gene-environment interactions in human germ cells. Mutation Research 667 70-76. (https://doi.org/10.1016/j.mrfmmm.2008.12.014)

Losos JB, Arnold SJ, Bejerano G, Brodie ED, Hibbett D, Hoekstra HE, Mindell DP, Monteiro A, Moritz C, Orr HA et al. 2013 Evolutionary biology for the 21st century. PLoS Biology 11 e1001466. (https://doi. org/10.1371/journal.pbio.1001466)

Lupold S \& Fitzpatrick JL 2015 Sperm number trumps sperm size in mammalian ejaculate evolution. Proceedings Biological Sciences 282 20152122. (https://doi.org/10.1098/rspb.2015.2122)

Macartney EL, Crean AJ \& Bonduriansky R 2018 Epigenetic paternal effects as costly, condition-dependent traits. Heredity $121248-256$. (https://doi.org/10.1038/s41437-018-0096-8)

Marshall DJ 2015 Environmentally induced (co)variance in sperm and offspring phenotypes as a source of epigenetic effects. Journal of Experimental Biology 218 107-113. (https://doi.org/10.1242/jeb.106427)

Mashoodh R, Habrylo IB, Gudsnuk KM, Pelle G \& Champagne FA 2018 Maternal modulation of paternal effects on offspring development. Proceedings Biological Sciences 285 20180118. (https://doi.org/10.1098/ rspb.2018.0118)

McAdam AG, Garant D \& Wilson AJ 2014 The effect of other's genes: maternal and other indirect genetic effects. In Quantitative Genetics in Natural Populations. Eds A Charmantier, D Garant \& L Kruuk. Oxford: Oxford University Press.

Miller D, Brinkworth M \& Iles D 2010 Paternal DNA packaging in spermatozoa: more than the sum of its parts? DNA, histones, protamines and epigenetics. Reproduction 139 287-301. (https://doi.org/10.1530/ REP-09-0281)

Mima M, Greenwald D \& Ohlander S 2018 Environmental toxins and male fertility. Current Urology Reports 19 50. (https://doi.org/10.1007/ s11934-018-0804-1)

Moore AJ, Brodie ED III \& Wolf JB 1997 Interacting phenotypes and the evolutionary process: I. Direct and indirect genetic effects of social interactions. Evolution, International Journal of Organic Evolution 51 1352-1362. (https://doi.org/10.1111/j.1558-5646.1997.tb01458.x)

Morrow EH, Leijon A \& Meerupati A 2008 Hemiclonal analyses reveals significant genetic, environmental and genotype $\times$ environment effects on sperm size in Drosophila melanogaster. Journal of Evolutionary Biology 21 1692-1702. (https://doi.org/10.1111/j.1420-9101.2008.01585.x)

Mousseau TA \& Fox CW 1998 Maternal Effects as Adaptations. Oxford: Oxford University Press.

Nargund VH 2015 Effects of psychological stress on male fertility. Nature Reviews Urology 12 373-382. (https://doi.org/10.1038/nrurol.2015.112)

Nesse RM \& Stearns SC 2008 The great opportunity: evolutionary applications to medicine and public health. Evolutionary Applications 1 28-48. (https://doi.org/10.1111/j.1752-4571.2007.00006.x)

Ng S-F, Lin RCY, Laybutt DR, Barres R, Owens JA \& Morris MJ 2010 Chronic high-fat diet in fathers programs (bgr)-cell dysfunction in female rat offspring. Nature 467 963-966. (https://doi.org/10.1038/ nature09491)

Norouzitallab P, Baruah K, Vandegehuchte M, Van Stappen G, Catania F, Vanden Bussche J, Vanhaecke L, Sorgeloos P \& Bossier P 2014 Environmental heat stress induces epigenetic transgenerational inheritance of robustness in parthenogenetic artemia model. FASEB Journal 28 3552-3563. (https://doi.org/10.1096/fj.14-252049)

Oakes CC, Smiraglia DJ, Plass C, Trasler JM \& Robaire B 2003 Aging results in hypermethylation of ribosomal DNA in sperm and liver of male rats. PNAS 100 1775-1780. (https://doi.org/10.1073/pnas.0437971100)

Öst A, Lempradl A, Casas E, Weigert M, Tiko T, Deniz M, Pantano L, Boenisch U, Itskov PM, Stoeckius M et al. 2014 Paternal diet defines offspring chromatin state and intergenerational obesity. Cell 159 1352-1364. (https://doi.org/10.1016/j.cell.2014.11.005)

Ostermeier GC, Dix DJ, Miller D, Khatri P \& Krawetz SA 2002 Spermatozoal RNA profiles of normal fertile men. Lancet 360 772-777. (https://doi.org/10.1016/S0140-6736(02)09899-9)

Ouko LA, Shantikumar K, Knezovich J, Haycock P, Schnugh DJ \& Ramsay M 2009 Effect of alcohol consumption on CpG methylation in the differentially methylated regions of H19 and IG-DMR in male gametes - implications for fetal alcohol spectrum disorders. Alcoholism, Clinical and Experimental Research 33 1615-1627. (https://doi. org/10.1111/j.1530-0277.2009.00993.x)

Pang TYC, Short AK, Bredy TW \& Hannan AJ 2017 Transgenerational paternal transmission of acquired traits: stress-induced modification of the sperm regulatory transcriptome and offspring phenotypes. Current Opinion in Behavioral Sciences 14 140-147. (https://doi.org/10.1016/j. cobeha.2017.02.007)

Parker GA 1979 Sexual selection and sexual conflict. In Sexual Selection and Reproductive Competition in Insects, pp 123-166. Eds MS Blum \& NA Blum. New York: Academic Press.

Pembrey ME, Bygren LO, Kaati G, Edvinsson S, Northstone K, Sjöström M, Golding J \& ALSPAC Study Team 2006 Sex-specific, male-line transgenerational responses in humans. European Journal of Human Genetics 14 159-166. (https://doi.org/10.1038/sj.ejhg.5201538)

Pitnick S, Hosken DJ \& Birkhead TR 2009 Sperm morphological diversity. In Sperm Biology: an Evolutionary Perspective, pp 69-149. Eds TR Birkhead, DJ Hosken \& S Pitnick. Burlington: Academic Press.

Polak M, Simmons LW, Benoit JB, Ruohonen K, Simpson SJ \& SolonBiet SM 2017 Nutritional geometry of paternal effects on embryo mortality. Proceedings Biological Sciences 284 20171492. (https://doi. org/10.1098/rspb.2017.1492)

Priest NK, Roach DA \& Galloway LF 2008 Cross-generational fitness benefits of mating and male seminal fluid. Biology Letters 4 6-8. (https:// doi.org/10.1098/rsbl.2007.0473)

Qvarnstrom A \& Price TD 2001 Maternal effects, paternal effects and sexual selection. Trends in Ecology and Evolution 16 95-100. (https:// doi.org/10.1016/S0169-5347(00)02063-2)

Rahman MM, Kelley JL \& Evans JP 2013 Condition-dependent expression of pre- and postcopulatory sexual traits in guppies. Ecology and Evolution 3 2197-2213. (https://doi.org/10.1002/ece3.632)

Rahman MM, Turchini GM, Gasparini C, Norambuena F \& Evans JP 2014 The expression of pre- and postcopulatory sexually selected traits reflects levels of dietary stress in guppies. PLOS ONE 9 e105856. (https://doi. org/10.1371/journal.pone.0105856)

Ramm SA, Edward DA, Claydon AJ, Hammond DE, Brownridge P, Hurst JL, Beynon RJ \& Stockley P 2015 Sperm competition risk drives plasticity in seminal fluid composition. BMC Biology 13 87. (https://doi.org/10.1186/ s12915-015-0197-2)

Reinhardt K, Dobler R \& Abbott J 2015 An ecology of sperm: sperm diversification by natural selection. In Annual Review of Ecology, Evolution, and Systematics, vol. 46, pp 435-459. Ed DJ Futuyma. (https:// doi.org/10.1146/annurev-ecolsys-120213-091611)

Ritchie H \& Marshall DJ 2013 Fertilisation is not a new beginning: sperm environment affects offspring developmental success. Journal of Experimental Biology 216 3104-3109. (https://doi.org/10.1242/jeb.087221)

Rodgers AB, Morgan CP, Bronson SL, Revello S \& Bale TL 2013 Paternal stress exposure alters sperm microRNA content and reprograms offspring HPA stress axis regulation. Journal of Neuroscience 33 9003-9012. (https://doi.org/10.1523/JNEUROSCI.0914-13.2013)

Rodgers AB, Morgan CP, Leu NA \& Bale TL 2015 Transgenerational epigenetic programming via sperm microRNA recapitulates effects of paternal stress. PNAS 112 13699-13704. (https://doi.org/10.1073/ pnas.1508347112)

Roff DA \& Wilson AJ 2014 Quantifying genetic by environmental interactions in laboratory systems. In Genotype-By-Environment Interactions and Sexual Selection, pp 101-136. Eds J Hunt \& DJ Hosken Oxford: UK.

Rompala GR, Mounier A, Wolfe CM, Lin QS, Lefterov I \& Homanics GE 2018 Heavy chronic intermittent ethanol exposure alters small noncoding RNAs in mouse sperm and epididymosomes. Frontiers in Genetics 9 32. (https://doi.org/10.3389/fgene.2018.00032)

Rowold ED, Schulze L, Van der Auwera S \& Grabe HJ 2017 Paternal transmission of early life traumatization through epigenetics: do fathers 
play a role? Medical Hypotheses 109 59-64. (https://doi.org/10.1016/j. mehy.2017.09.011)

Royle NJ 2012 The Evolution of Parental Care. Oxford: Oxford University Press.

Saavedra-Rodriguez L \& Feig LA 2013 Chronic social instability induces anxiety and defective social interactions across generations. Biological Psychiatry 73 44-53. (https://doi.org/10.1016/j.biopsych.2012.06.035)

Schagdarsurengin U \& Steger K 2016 Epigenetics in male reproduction: effect of paternal diet on sperm quality and offspring health. Nature Reviews Urology 13 584-595. (https://doi.org/10.1038/nrurol.2016.157)

Serre V \& Robaire B 1998 Paternal age affects fertility and progeny outcome in the Brown Norway rat. Fertility and Sterility 70 625-631. (https://doi. org/10.1016/S0015-0282(98)00259-3)

Sharma R, Agarwal A, Rohra VK, Assidi M, Abu-Elmagd M \& Turki RF 2015 Effects of increased paternal age on sperm quality, reproductive outcome and associated epigenetic risks to offspring. Reproductive Biology and Endocrinology 13 35. (https://doi.org/10.1186/s12958-015-0028-x)

Sharma U, Conine CC, Shea JM, Boskovic A, Derr AG, Bing XY, Belleannee C, Kucukural A, Serra RW, Sun FY et al. 2016 Biogenesis and function of tRNA fragments during sperm maturation and fertilization in mammals. Science 351 391-396. (https://doi.org/10.1126/science. aad6780)

Sharma U, Sun F, Conine CC, Reicholf B, Kukreja S, Herzog VA, Ameres SL \& Rando OJ 2018 Small RNAs are trafficked from the epididymis to developing mammalian sperm. Developmental Cell 46 481-494.e6. (https://doi.org/10.1016/j.devcel.2018.06.023)

Sharpe RM 2010 Environmental/lifestyle effects on spermatogenesis. Philosophical Transactions of the Royal Society B: Biological Sciences 365 1697-1712. (https://doi.org/10.1098/rstb.2009.0206)

Sheldon BC 2000 Differential allocation: tests, mechanisms and implications. Trends in Ecology and Evolution 15 397-402. (https://doi. org/10.1016/S0169-5347(00)01953-4)

Shi C \& Murphy CT 2014 Mating induces shrinking and death in Caenorhabditis mothers. Science 343 536-540. (https://doi.org/10.1126/ science.1242958)

Siklenka K, Erkek S, Godmann M, Lambrot R, McGraw S, Lafleur C, Cohen T, Xia JG, Suderman M, Hallett M et al. 2015 Disruption of histone methylation in developing sperm impairs offspring health transgenerationally. Science $\mathbf{3 5 0}$ aab2006. (https://doi.org/10.1126/ science.aab2006)

Simmons LW \& Beveridge M 2011 Seminal fluid affects sperm viability in a cricket. PLOS ONE 6 e17975. (https://doi.org/10.1371/journal. pone.0017975)

Simmons LW \& Garcia-Gonzalez F 2007 Female crickets trade offspring viability for fecundity. Journal of Evolutionary Biology 20 1617-1623. (https://doi.org/10.1111/j.1420-9101.2007.01320.x)

Simmons LW \& Lovegrove M 2017 Socially cued seminal fluid gene expression mediates responses in ejaculate quality to sperm competition risk. Proceedings Biological Sciences 28420171486 . (https://doi. org/10.1098/rspb.2017.1486)

Singh RS 2003 Comment on 'Epigenetics and the renaissance of heresy'. Genome 46 968-972. (https://doi.org/10.1139/g03-116)

Soubry A 2015 Epigenetic inheritance and evolution: a paternal perspective on dietary influences. Progress in Biophysics and Molecular Biology 118 79-85. (https://doi.org/10.1016/j.pbiomolbio.2015.02.008)

Soubry A, Hoyo C, Jirtle RL \& Murphy SK 2014 A paternal environmental legacy: evidence for epigenetic inheritance through the male germ line. BioEssays 36 359-371. (https://doi.org/10.1002/bies.201300113)

Spadafora C 2018 The 'evolutionary field' hypothesis. Non-Mendelian transgenerational inheritance mediates diversification and evolution. Progress in Biophysics and Molecular Biology 134 27-37. (https://doi. org/10.1016/j.pbiomolbio.2017.12.001)

Tarin JJ, Perez-Albala S \& Cano A 2000 Consequences on offspring of abnormal function in ageing gametes. Human Reproduction Update 6 532-549. (https://doi.org/10.1093/humupd/6.6.532)

Uller T, Nakagawa S \& English S 2013 Weak evidence for anticipatory parental effects in plants and animals. Journal of Evolutionary Biology $\mathbf{2 6}$ 2161-2170. (https://doi.org/10.1111/jeb.12212)

Uriah N, Ibeh IN \& Oluwafemi F 2001 A study onf the impact of aflatoxin on human reproduction. African Journal of Reproductive Health $\mathbf{5}$ 106-110. (https://doi.org/10.2307/3583204)
Valcarce DG, Vuelta E, Robles V \& Herraez MP 2017 Paternal exposure to environmental 17-alpha-ethinylestradiol concentrations modifies testicular transcription, affecting the sperm transcript content and the offspring performance in zebrafish. Aquatic Toxicology 193 18-29. (https://doi.org/10.1016/j.aquatox.2017.09.025)

Varmuza S 2003 Epigenetics and the renaissance of heresy. Genome $\mathbf{4 6}$ 963-967; discussion 968. (https://doi.org/10.1139/g03-115)

Vermeulen A, Engels S, Engqvist L \& Sauer KP 2009 Phenotypic plasticity in sperm traits in scorpionflies (Mecoptera: Panorpidae): consequences of larval history and seasonality on sperm length and sperm transfer. European Journal of Entomology 106 347-352. (https://doi.org/10.14411/ eje.2009.042)

Wang Y, Liu HJ \& Sun ZS 2017 Lamarck rises from his grave: parental environment-induced epigenetic inheritance in model organisms and humans. Biological Reviews of the Cambridge Philosophical Society 92 2084-2111. (https://doi.org/10.1111/brv.12322)

Wedell N, Gage MJG \& Parker GA 2002 Sperm competition, Male prudence and sperm-limited females. Trends in Ecology and Evolution 17 313-320. (https://doi.org/10.1016/S0169-5347(02)02533-8)

Wei YC, Yang CR, Wei YP, Zhao ZA, Hou Y, Schatten H \& Sun QY 2014 Paternally induced transgenerational inheritance of susceptibility to diabetes in mammals. PNAS 111 1873-1878. (https://doi.org/10.1073/ pnas.1321195111)

White J, Wagner RH, Helfenstein F, Hatch SA, Mulard H, Naves LC \& Danchin E 2008 Multiple deleterious effects of experimentally aged sperm in a monogamous bird. PNAS 105 13947-13952. (https://doi. org/10.1073/pnas.0803067105)

Wigby S \& Chapman T 2005 Sex peptide causes mating costs in female Drosophila melanogaster. Current Biology 15 316-321. (https://doi. org/10.1016/j.cub.2005.01.051)

Willham RL 1963 The covariance between relatives for characters composed of components contributed by related individuals. Biometrics 19 18-27. (https://doi.org/10.2307/2527570)

Wilson AJ, Reale D, Clements MN, Morrissey MM, Postma E, Walling CA, Kruuk LE \& Nussey DH 2010 An ecologist's guide to the animal model. Journal of Animal Ecology 79 13-26. (https://doi.org/10.1111/j.13652656.2009.01639.x)

Wimmer ME, Briand LA, Fant B, Guercio LA, Arreola AC, Schmidt HD, Sidoli S, Han Y, Garcia BA \& Pierce RC 2017 Paternal cocaine taking elicits epigenetic remodeling and memory deficits in male progeny. Molecular Psychiatry 22 1641-1650. (https://doi.org/10.1038/mp.2017.8)

Wolf JB \& Wade MJ 2009 What are maternal effects (and what are they not)? Philosophical Transactions of the Royal Society B: Biological Sciences 364 1107-1115. (https://doi.org/10.1098/rstb.2008.0238)

Wolf JB, Brodie ED, Cheverud JM, Moore AJ \& Wade MJ 1998 Evolutionary consequences of indirect genetic effects. Trends in Ecology and Evolution 13 64-69. (https://doi.org/10.1016/S0169-5347(97)01233-0)

Wolfner MF 2002 The gifts that keep on giving: physiological functions and evolutionary dynamics of male seminal proteins in Drosophila. Heredity 88 85-93. (https://doi.org/10.1038/sj.hdy.6800017)

Wolfner MF 2009 Battle and ballet: molecular interactions between the sexes in Drosophila. Journal of Heredity 100 399-410. (https://doi. org/10.1093/jhered/esp013)

Wong CL, Lee KH, Lo KM, Chan OC, Goggins W, O WS \& Chow PH 2007 Ablation of paternal accessory sex glands imparts physical and behavioural abnormalities to the progeny: an in vivo study in the golden hamster. Theriogenology 68 654-662. (https://doi.org/10.1016/j. theriogenology.2007.04.062)

Xie K, Ryan DP, Pearson BL, Henzel KS, Neff F, Vidal RO, Hennion M, Lehmann I, Schleif M, Schroder S et al. 2018 Epigenetic alterations in longevity regulators, reduced life span, and exacerbated aging-related pathology in old father offspring mice. PNAS 115 E2348-E2357. (https:// doi.org/10.1073/pnas.1707337115)

Xing Y, Shi S, Le L, Lee CA, Silver-Morse L \& Li WX 2007 Evidence for transgenerational transmission of epigenetic tumor susceptibility in Drosophila. PLoS Genetics 3 1598-1606. (https://doi.org/10.1371/ journal.pgen.0030151)

Zajitschek S, Hotzy C, Zajitschek F \& Immler S 2014 Short-term variation in sperm competition causes sperm-mediated epigenetic effects on early offspring performance in the zebrafish. Proceedings Biological Sciences 281 20140422. (https://doi.org/10.1098/rspb.2014.0422) 
Zajitschek S, Herbert-Read JE, Abbasi NM, Zajitschek F \& Immler S 2017 Paternal personality and social status influence offspring activity in zebrafish. BMC Evolutionary Biology 17 157. (https://doi.org/10.1186/ s12862-017-1005-0)

Zajitschek SRK, Dowling DK, Head ML, Rodriguez-Exposito E \& Garcia-Gonzalez F 2018 Transgenerational effects of maternal sexual interactions in seed beetles. Heredity 121 282-291. (https://doi. org/10.1038/s41437-018-0093-y)

Zuccolo L, DeRoo LA, Wills AK, Smith GD, Suren P, Roth C, Stoltenberg C \& Magnus P 2016 Pre-conception and prenatal alcohol exposure from mothers and fathers drinking and head circumference: results from the
Norwegian mother-child study (MoBa). Scientific Reports 639535. (https://doi.org/10.1038/srep39535)

Received 3 October 2018

First decision 26 November 2018

Revised manuscript received 8 January 2019

Accepted 21 January 2019 